\title{
Intersecciones nación-provincia en contexto electoral. Coaliciones políticas y doble- agentes en San Juan, Argentina, durante las elecciones 2019
}

Nation-province intersections in an electoral context. Political coalitions and double-agents in San Juan, Argentina, during the 2019 elections.

Intersecções nação-província no contexto eleitoral. Coalizões políticas e agentes duplos em San Juan, Argentina, durante as eleições de 2019

Flavia Cecilia Prado* , Víctor Hugo Algañaraz Soria**

\section{RESUMEN}

Desde un enfoque cualitativo de la sociología política, este arPalabras clave: tículo procura contribuir a (re)conocer la relevancia de los escoaliciones pacios subnacionales en el entramado político nacional. El foco electorales, analítico está puesto en la reciente contienda electoral de Argentina y, especialmente, en sus puntos de intersección con la política partidaria de la Provincia de San Juan. La investigación incluyó análisis de información documental, examen de bases de datos electorales, realización de entrevistas y análisis de discurso de actores políticos relevantes. El argumento principal del trabajo sostiene que la institucionalización de la dinámica electoral convergencia multinivel, elecciones nacionales, política subnacional, Provincia de San Juan. devino en un espacio de importantes convergencias y concu-

\footnotetext{
* Argentina. Licenciada en Sociología por la Universidad Nacional de San Juan y Doctoranda en Ciencias Sociales por la Universidad Nacional de Cuyo, Argentina. Instituto de Investigaciones Socio-económicas, Universidad Nacional de San Juan y Consejo Nacional de Investigaciones Científicas y Técnicas (CONICET), CCT San Juan-Argentina. San Juan, Argentina. flaviacprado@gmail.com

** Argentino. Licenciado en Sociología por la Universidad Nacional de San Juan y Doctor en Ciencias Sociales por la Universidad Nacional de Cuyo, Argentina. Instituto de Investigaciones Socio-económicas, Universidad Nacional de San Juan y Consejo Nacional de Investigaciones Científicas y Técnicas (CONICET), CCT San Juan-Argentina. San Juan, Argentina. victor.algz@gmail.com
} 
rrencias de actores, partidos y coaliciones políticas, que acumularon/construyeron poder de un modo situado, reconfigurando el escenario político subnacional e incidiendo relativamente en el entramado nacional a partir del rol de ciertos doble-agentes.

\begin{abstract}
From a qualitative approach to political sociology, this article seeks to contribute to (re)understanding the relevance of subnational spaces in the national political framework. The analytical focus is on the recent electoral contest in Argentina and, especially, on where it intersects with party politics in the province of San Juan. The research included analysis of documentary information, examination of electoral databases, interviews and discourse analysis of relevant political actors. The main argument of the paper is that the institutionalization of electoral dynamics has become a space where actors, parties and political coalitions converge and concur, where they accumulated/constructed power in a particular way, reconfiguring the subnational political scenario and influencing the national framework through the role of certain double-agents.
\end{abstract}

\section{RESUMO}

A partir de uma abordagem qualitativa da sociologia política, este artigo procura contribuir para (re)conhecer a relevância dos espaços subnacionais na estrutura política nacional. $\mathrm{O}$ foco analítico é colocado na recente disputa eleitoral na Argentina e, especialmente, em seus pontos de intersecção com a política partidária da Província de San Juan. A pesquisa incluiu análise de informação documental, avaliação de bancos de dados eleitorais, realização de entrevistas e análise do discurso de atores políticos relevantes. O principal argumento do trabalho é que a institucionalização da dinâmica eleitoral se tornou um espaço de importantes convergências e pontos de encontro de atores, partidos e coalizões políticas, que acumularam/construíram o poder de forma situada, reconfigurando o cenário político subnacional e com relativo impacto no quadro nacional a partir do papel de certos agentes duplos.
Keywords:

electoral

coalitions, multilevel convergence, national elections, subnational politics, San Juan Province.

Palavras-chave: coalizões eleitorais, convergência em múltiplos níveis, eleições nacionais, política subnacional, Província de San Juan. 


\section{Introducción}

El abordaje de los procesos políticos provinciales en Argentina viene consolidándose como campo específico de estudio en las ciencias sociales desde hace un largo tiempo, pero recientemente ha cobrado un renovado y creciente impulso. La recuperación de la "escala subnacional" como dimensión analítica en los procesos de investigación social resulta relevante para una comprensión más plural de los contextos democráticos y federales, esencialmente complejos. Permite dar cuenta de la especificidad de estos en un territorio dado y coadyuva a determinar su convergencia en fenómenos políticos habitualmente construidos/interpretados en una escala nacional. Inscripto en esta tendencia, el presente artículo procura contribuir a (re)conocer la relevancia de los espacios subnacionales en el entramado nacional, mostrando cómo ciertos actores políticos, partidos y/o coaliciones que han acumulado poder de modo situado, lo construyeron de forma relativamente autónoma, pero relacional respecto de otros niveles.

Desde una perspectiva cualitativa de la sociología política, este artículo focaliza como caso de estudio en la Provincia de San Juan, territorio subnacional de la República Argentina, considerado muchas veces "periférico" en el sistema político nacional, dado fundamentalmente su escaso peso cuantitativo en el padrón electoral de la nación. Sin embargo, este trabajo mostrará que resulta un caso de análisis interesante en términos cualitativos, en tanto el orden político aquí configurado no funcionó como una mera red de relaciones de cooperación y competencia provincial, donde sin dudas anidaron los márgenes de consagración/permanencia de ciertos actores y fuerzas políticas en cargos de gestión, sino que su dinámica fue mucho más compleja, traspasando su inserción territorial y enriqueciendo la trama del juego nacional.

Con un color político diferente del entonces gobierno vigente en la escala nacional, el oficialismo de San Juan encaró un ambicioso modelo de unidad política resultando victorioso en el proceso eleccionario del 2019. Frente Todos fue el nombre de la coalición encabezada por el Partido Justicialista (PJ) provincial que, incluyendo piezas de articulación intra y extrapartidarias, pasó de ser elogiada por referentes nacionales a ser emulada en la conformación del llamado Frente de Todos cuya fórmula presidencial Fernández-Fernández propició el reingreso del kirchnerismo/peronismo al Poder Ejecutivo Nacional. 
Ciertos actores políticos provinciales desplegaron, en este marco, un rol de doble-agentes. Stefuriuc (2009) ha identificado como tales a aquellos actores, partidos y/o frentes que participan activamente de entramados políticos provinciales y nacionales. Se trata de actores que "habitan" el juego político en las escalas nacional y provincial de gobierno, a partir de su rol en las instituciones formales del régimen federal. Este fue el caso, por ejemplo, del histórico dirigente peronista y exgobernador de San Juan José Luis Gioja. Sobre la base de su trayectoria y, fundamentalmente, a partir de su accionar como presidente del PJ Nacional y proximidad con sectores kirchneristas, fue uno de los bastiones primordiales de la oposición al anterior gobierno de Mauricio Macri y uno de los cinceles principales que lograron labrar la unidad del PJ a nivel nacional y salir victoriosos en el proceso electoral. También el gobernador de San Juan, Sergio Uñac, desempeñó un importante rol en el mismo sentido: además de ser presidente del PJ Provincial, logró cultivar en líneas generales buenas relaciones con el oficialismo de Macri a nivel nacional y, manteniéndose equidistante de los innumerables conflictos intraperonistas de los últimos años, entabló vínculos cordiales con importantes referentes políticos nacionales como Sergio Massa o Roberto Lavagna, acercándose finalmente a la figura de la expresidenta (hoy vicepresidenta) Cristina Fernández de Kirchner. Su perfil político cobró tal relevancia durante el contexto electoral, que incluso su nombre comenzó a esbozarse como una figura de proyección nacional.

El argumento central que guía este trabajo sostiene que: la institucionalización de la dinámica electoral durante el 2019 en San Juan devino en un espacio de importantes convergencias y concurrencias de actores, partidos y coaliciones políticas que acumularon/construyeron poder de un modo situado, reconfigurando el escenario político subnacional e incidiendo relativamente en el entramado nacional a partir del rol de ciertos doble-agentes. En este sentido, podría pensarse que el armado de la alianza política electoral que encaró el PJ Provincial — que gobierna el territorio desde 2003 hasta la fecha- sirvió como antesala para el rearmado de la plataforma política con la que el PJ Nacional logró arrebatarle el sillón presidencial a Mauricio Macri. El proceso de armado de este modelo de unidad fue complejo y estuvo signado no solo por las condiciones estructurales en las que se produjo sino también, y fundamentalmente, por las prácticas interactivas y ne- 
gociadas de los distintos participantes (individuales y colectivos) en las escalas subnacional y nacional. Un armado político en el que también los actores y fuerzas de la oposición fueron partícipes activos, ya sea mediante estrategias de adaptación o resistencia, o bien, por medio de posiciones intermedias y brechas de intervención.

En este marco, resulta relevante estudiar empíricamente la dinámica electoral de esta región argentina y su impacto en la escala nacional, focalizando en el rol desempeñado por las principales fuerzas políticas en juego y el complejo entramado de alianzas partidarias que tuvieron lugar allí. Para ello, se han articulado diferentes accesos metodológicos: indagación de información documental, examen de bases de datos electorales (nacionales, provinciales y municipales) y realización de entrevistas y análisis de discursos de actores políticos relevantes.

\section{Perspectivas teóricas y antecedentes del tema}

Durante las últimas décadas, el campo de estudios políticos subnacionales viene expandiéndose sostenidamente. Se trata de un paradigma epistemológico relevante que, desde diferentes tradiciones disciplinares (vinculadas con la ciencia política, la historia y la sociología, principalmente), ha avanzado en complejizar y enriquecer las miradas y reflexiones respecto del Estado, los gobiernos, partidos y élites políticas, así como las diversas formas de articulación de los actores políticos con la sociedad en los espacios provinciales, incidiendo indefectiblemente en la construcción de las agendas de investigación referidas a los fenómenos políticos nacionales. De allí que en esta sección del trabajo se recuperen los principales aportes de la literatura disponible, identificando los puntos nodales de sus enfoques en los planos internacional, nacional y subnacional, en tanto contribuciones sustanciales para situar teórica y empíricamente la temática en estudio.

En primer lugar, cabe destacar que la discusión internacional acerca del tema es prolífica y de larga data, destacándose los trabajos de Albright (2010), Battle (2009), Bechtel (2012), Behrend (2011), Došek y Freidenberg (2013), Freidenberg y Suárez-Cao (2014), Gibson (2012), Jeffery y Schakel (2012), Lodola (2010), Micozzi (2009), y Snyder (2001) entre los diversos avances teóricos que apuntalaron la deconstrucción del locus político como un mero objeto de investigación de orden "nacional", resquebrajando así el "nacionalismo meto- 
dológico" imperante. En términos generales, el grueso de estos trabajos comparte como argumento común considerar que los procesos políticos devenidos a nivel subnacional no asumen necesariamente un carácter "de segundo orden", siendo procesos igual de relevantes para comprender las dinámicas políticas de los estados multinivel. Distanciándose de la literatura comparada tradicional, que generalmente ha examinado los procesos electorales y sistemas de partidos con cierto "sesgo nacional", coinciden en señalar la necesidad de avanzar en estudios concretos relativos a las interacciones que se dan tanto entre los niveles nacional y subnacional (perspectiva vertical de indagación), así como entre los ámbitos subnacionales (perspectiva horizontal de indagación), dando paso así a una interpretación integral de los contextos multinivel propios de países con una estructura federal, como es el caso de Argentina.

En segundo lugar, respecto del estado del arte en Argentina específicamente, cabe señalar que desde diferentes disciplinas y enfoques ciertos autores/as han enriquecido también el conocimiento de los contextos y prácticas situadas en ámbitos provinciales. En efecto, entre la amplia literatura especializada y disponible referente a política subnacional en el país, se destacan los trabajos de Aelo (2010), Benton (2009), Bonvecchi y Lodola (2011), Calvo y Abal Medina (2001), Calvo y Escolar (2005), Cherny y Vommaro (2004), Cruz (2014), Ferrari y Mellado (2015), Frederic y Soprano (2009), Gervasoni (2011), Gibson y Suárez-Cao (2010), Leiras (2006), Mauro (2020), Mauro et al. (2016) y Rodrigo (2014), y otro conjunto de trabajos más heterogéneo focalizados en el análisis de distritos particulares, principalmente los correspondientes a la Provincia de Buenos Aires y Ciudad Autónoma de Buenos Aires. La mayoría de estas obras presentan núcleos temáticos y problemáticos análogos: las identidades partidarias, la construcción de liderazgos políticos y las dinámicas de participación ciudadana en esferas subnacionales. Entre otros señalamientos comunes, destacan la importancia de comprender las interacciones entre los diferentes niveles políticos y distritos, incorporando el anclaje subnacional como unidad de análisis. Al decir de Victoria Ortiz de Rozas (2016):

la adopción de una escala subnacional de análisis ha permitido observar las 'variaciones' territoriales de un mismo fenómeno po- 
lítico, pero también ha permitido complejizar y cuestionar las interpretaciones acerca de la democracia argentina construida en un nivel de análisis 'nacional'. (p. 339).

En este sentido, el conjunto de estos estudios ha coadyuvado a derribar la prenoción de que las diversas realidades provinciales solo pueden comprenderse atendiendo a su lógica endógena diferente o distante de la nacional, diluyendo también la idea de un "derrame" de la dinámica política nacional sobre los entornos subnacionales y la creencia de que, como partes de un todo, no son sino un mero "reflejo" de procesos que deben ser interpretados a nivel macro. Recuperando también el argumento de Leiras (2006), podríamos decir que la política es un juego complejo que se despliega en múltiples tableros y que cualquier jugada en alguno de ellos repercutirá sobre la posición del jugador en los otros tableros: "los resultados del juego en un nivel, afectan los resultados en otros niveles" (p. 9).

En tercer lugar, cabe referirnos a los aportes de la literatura especializada a nivel provincial. Sobre ello vale señalar que, aunque los estudios subnacionales se han desarrollado en varias direcciones en el país, muy pocos han focalizado desde esta perspectiva de análisis en el distrito de San Juan. Por un lado, se destaca un grupo de autores/as que parte de reconocer el bipartidismo tradicional del país cristalizado en la monopolización de la competencia electoral por las dos históricas fuerzas nacionales que constituyen la Unión Cívica Radical (UCR) y el Partido Justicialista (PJ), aunque se han concentrado especialmente en torno al devenir de ciertos partidos políticos provinciales (Bloquismo y Cruzada Renovadora) nacidos como desmembramientos de fuerzas nacionales, pero al amparo de circunstancias subnacionales. En esta línea, se destacan los trabajos de Goldberg, Castilla et al. (2007; 2009), Gómez y Goldberg (2013), Pereyra y Vasini (1994), Veramendi (2009), que, en términos generales, han coadyuvado a demostrar que, desde el retorno de la democracia en 1983, las fuerzas políticas provinciales más que perder poder y presencia en el escenario electoral, partidario y político han reconfigurado sus perspectivas y horizontes en la búsqueda de alcanzar una mayor participación en instancias electorales y detentar así cargos públicos. Al decir de Veramendi (2009):

Estos partidos siguen expresando un sentir y realidad autóctono que difícilmente los partidos nacionales puedan suplantar. Es de 
esperar entonces que, así como en el mundo globalizado lo local sigue presente y se expresa de diversas formas; la política a nivel subnacional encuentre vías "sui generis" de sostener su voz en un sistema de partidos predominante o hegemónico. (p. 227).

Por otro lado, se encuentra un grupo de trabajos focalizados en la historia política reciente de la provincia, como los de Cao (2013), Ceretti et al. (2015), Puente (2017), Rodrigo (2019; 2018) y Ruffa y López (2005) que abordan aspectos centrales del régimen democrático como el "sanjuaninazo"; el enjuiciamiento político a gobernadores; los comportamientos ciudadanos; y otras características más recientes del sistema de partidos. El común denominador de estos trabajos es considerar a San Juan como una arena política de relevancia subnacional y nacional, señalando que ha devenido en un distrito gobernado no por una familia política ni un único partido, sino por una alianza de actores políticos de diferentes escalas que han generado en años recientes redes ambiguas de competencia y colaboración a nivel de las instancias electorales y del mismo sistema de gobierno. Al respecto, Cintia Rodrigo (2019) ha señalado que: "contra la imagen predominante sobre las provincias periféricas, San Juan muestra como rasgos característicos la alternancia y la inestabilidad política" (p. 23).

En suma, el trabajo investigativo que aquí se presenta adopta el enfoque de la sociología política y su mirada atenta sobre los ámbitos provinciales/locales de producción de lo político, que se viene consolidando en los últimos años tanto a nivel internacional, como nacional y propiamente subnacional. En consonancia con este corpus teórico, consideramos relevante indagar las dinámicas particulares de territorios más delimitados, pues estas contribuyen fuertemente a delinear las características del entramado político nacional. En relación con dicho enfoque, Ortiz de Rozas y Rodrigo (2017) han indicado que:

La sociología se ha interesado en las trayectorias de los actores políticos, las formas de selección y reclutamiento de las élites políticas provinciales y las configuraciones organizacionales de los partidos provinciales. Estos aportes disciplinares contribuyeron a consolidar un consenso académico sobre la especificidad que adquieren la democracia, el Estado y los actores sociales en los distintos territorios, así como las relaciones complejas que se establecen entre las distintas arenas provinciales y locales, o incluso entre el nivel 
provincial y niveles de mayor agregación, como nacional o supranacional. (p. 10).

Así, sobre la base de los estudios reseñados, el presente artículo procura indagar en el comportamiento electoral reciente en San Juan, Argentina, identificando los trazos más importantes de las coaliciones políticas intervinientes y el rol de doble-agentes desplegado por ciertos actores políticos que, aunque situados en la esfera subnacional, construyeron relaciones de poder relacionales respecto de la esfera nacional. En particular, se recuperará la propuesta de Aelo (2010) y su concepción acerca del locus subnacional, como un terreno de producción de lo político, un espacio donde se construyen experiencias y aplican determinadas prácticas, que en mayor o menor medida inciden en el entramado nacional. Desde esta perspectiva consideramos que si bien la política nacional interpela cada una de las provincias, sus implicancias son siempre diferenciales dadas sus singularidades políticoinstitucionales, devenir histórico y propia correlación de fuerzas, que serán precisamente las dimensiones analíticas que guiarán la indagación del caso sanjuanino. Estimamos que abordar las configuraciones subnacionales aporta diversidad e integralidad al estudio más general referido al entramado político nacional.

\section{Metodología}

El presente artículo es abordado desde un enfoque cualitativo de la sociología política y focaliza en la Provincia de San Juan como caso de estudio instrumental. Como tal, no parte de un modelo teórico predefinido, sino que busca repensar las relaciones entre actores, partidos políticos y contexto local como elementos constitutivos del fenómeno estudiado. En este sentido, se prioriza el seguimiento/rastreo de las relaciones entabladas entre los diferentes actores en sus propios escenarios de interacción, focalizando especialmente en un nivel de análisis poco observado hasta ahora, como es el ámbito subnacional sanjuanino. De allí que el caso sea abordado de manera intensa y profunda, como un "sistema acotado" a los límites del territorio político en estudio, pero a la vez expandido dadas sus imbricaciones con la escala nacional en el contexto electoral. En cuanto al recorte temporal, si bien el escrito focaliza específicamente en la contienda electoral 2019, dada la perspectiva sociológica de análisis, en determinados momentos se 
desplegará un ángulo más amplio de indagación que posibilite interpretar procesos recientes, pero que responden a una lógica política estructural de una duración más extensa.

Respecto de la estrategia de investigación que constituye el estudio de caso, ella se seleccionó porque permite explorar la singularidad de la arena política en la provincia de San Juan y desde allí coadyuvar a comprender la complejidad del fenómeno electoral a escala nacional, a partir de reconocer, precisamente, sus intersecciones. De acuerdo con Marradi et al. (2007), la potencialidad del estudio de caso se intensifica al situarse entre los diseños cualitativos, permitiendo alcanzar una mayor profundidad analítica y ahondar en la complejidad del y/o los fenómenos examinados.

En cuanto al abordaje del caso sanjuanino en particular, cabe destacar que fue seleccionado a partir de sus propias características histórico-institucionales que lo constituyeron como un espacio político de interés teórico y empírico, a saber:

- durante la contienda electoral 2019, y con un color político diferente al del entonces gobierno nacional, en San Juan se estableció una coalición política estimulada y comandada por el PJ Provincial, pero abierta a actores y fuerzas políticas diversas, resultando victoriosa;

- ciertos actores políticos provinciales, como Gioja y Uñac, desempeñaron en este contexto un rol de doble-agentes, desplegando líneas paralelas de actividad en las esferas nacional y subnacional;

- la plataforma política del PJ Nacional reconoció como antesala de su éxito electoral las prácticas interactivas y negociadas del entramado político del PJ sanjuanino, y en ambos casos las coaliciones correspondientes se denominaron Frente de Todos.

Dadas entonces las características del escenario político sanjuanino, el método de estudio de caso resulta conducente al permitir referir una situación particular tomada en su contexto y analizarla para ver cómo se manifiesta el o los fenómenos de interés. Respecto de ello, Yin (1994) ha señalado que:

Una investigación de estudio de caso trata con una situación técnicamente distintiva en la cual hay muchas más variables de interés que datos observacionales; y, como resultado, se basa en múltiples 
fuentes de evidencia, con datos que deben converger en un estilo de triangulación; y, también como resultado, se beneficia del desarrollo previo de proposiciones teóricas que guían la recolección y el análisis de datos. (p. 13).

En esa dirección se ha desplegado precisamente el presente estudio de caso, que constituye un estudio estructural-descriptivo, centrado en la búsqueda, recolección y análisis de información diversa que posibilite referir a las posiciones y tomas de posición de las fuerzas políticas provinciales, y sus principales actores, durante las elecciones 2019. Para ello, se ha adoptado un diseño de investigación flexible e interactivo, desplegando una estructura interconectada de las distintas fases del estudio y articulando diversas técnicas de registro y análisis de datos (Piovani y Muñiz Terra, 2018). En este marco, uno de los principales accesos metodológicos lo constituyó el análisis de información documental (Dulzaides y Molina, 2014), cristalizado en la recuperación/indagación de un cuerpo de fuentes secundarias: documentos públicos e institucionales como leyes, decretos, normativas electorales, notas periodísticas en medios provinciales y nacionales y, fundamentalmente, estadísticas públicas provenientes de la Cámara Nacional Electoral, el Tribunal Electoral Provincial y datos electorales de los 19 municipios que integran el distrito sanjuanino. En complemento, se desplegó también un acceso metodológico "testimonial", tendiente a recuperar las experiencias y memorias contenidas en los relatos de referentes políticos destacados. Para ello, en los casos que fue posible se realizaron entrevistas de primera mano de carácter semiestructuradas conforme a un criterio teórico, o bien, se procedió a realizar un análisis de discurso, sistematizando y examinando sus intervenciones orales en diversos medios de divulgación. La finalidad fue "recoger hechos del habla y construir con ellos un corpus de categorías que adquieren sentido en relación con los usos principales que, desde las hipótesis de investigación, orientan el discurso de los enunciantes" (Alonso, 1999, p. 207).

De acuerdo con la lógica metodológica planteada, antes que seguir un proceso inferencial-hipotético, este estudio privilegió un proceder empírico orientado por una pregunta referencial y el objetivo general de la indagación: examinar en qué medida el proceso electoral devenido en 2019 en San Juan cristalizó en un espacio de convergencias y concurrencias de actores, partidos y coaliciones políticas que, aunque 
construyeron poder de un modo situado, incidieron relativamente en el entramado nacional a partir del rol desplegado por ciertos dobleagentes. Un aspecto para resaltar es que las categorías de análisis de las entrevistas, discursos y documentos examinados no fueron definidas previamente, sino que emergieron al inmiscuirnos en el corpus textual. En palabras de Santander (2011) "en tanto nos enfrentamos a los textos, van emergiendo categorías pertinentes con las cuales analizamos y conceptualizamos nuestro conocimiento obtenido" (p. 214). Queda por destacar que, al igual que la transcripción de documentos, la utilización de determinados fragmentos de testimonios orales bajo la forma de citas constituye, de acuerdo con Sautu (2003), una herramienta metodológica válida en todo escrito científico, pues posibilita (re)conocer y comprender las posiciones sostenidas por los actores sociales indagados.

\section{Análisis y resultados}

La matriz política en San Juan: apuntes sobre su configuración histórica

Situada al centro-oeste de la República Argentina y a los pies de la cordillera de los Andes, la Provincia de San Juan comprende $89.651 \mathrm{~km}^{2}$ (representando el 3,2\% del territorio nacional) y según datos proyectados del Censo Nacional 2010, su población alcanzó los 772.876 habitantes en 2019. En cuanto a sus características político-institucionales, constituye uno de los 24 distritos políticos del país, gozando de la autonomía relativa y facultades otorgadas por la Constitución Nacional para dictar y modificar sus propias leyes, que conviven y se articulan con las reglamentaciones de orden nacional ${ }^{1}$. Dada la cantidad total de sanjuaninos habilitados para sufragar en las elecciones 2019, estimada en 557.166 ciudadanos, esta provincia ocupó el $13^{\circ}$ lugar del padrón electoral nacional alcanzando el 1,66\% de representatividad: siendo 288.848 las mujeres y 272.359 los varones, según datos de la Cámara Nacional Electoral (CNE, 2019). De esta manera, se ubicó en el grupo de provincias con menos del $2 \%$ de electores (junto con los distritos de Jujuy, Río Negro y Neuquén, entre otros) y a mucha distancia de

1 Ver Cámara de Diputados de San Juan (2014a) y Ley No 8.520 Nuevo Código Electoral de la Provincia de San Juan en Cámara de Diputados de San Juan (2014b). 
los mayores distritos electorales del país como Buenos Aires (37\%), Córdoba (8,7\%), Santa Fe (8,15\%), Ciudad Autónoma de Buenos Aires $(7,6 \%)$ y Mendoza $(4,2 \%)$. Pero como hemos visto en apartados precedentes, focalizar en el espacio subnacional sanjuanino resulta un caso interesante más bien en términos cualitativos, dadas las características de la contienda electoral y singularidades del orden político aquí configurado.

Partiendo de estos señalamientos generales, y sin pretensiones de una periodización holística, esta sección del trabajo procura aportar a la comprensión del proceso eleccionario 2019 en San Juan, ahondando en la configuración histórica de las principales fuerzas políticas (frentes, coaliciones y partidos) que entraron en disputa, identificando los principales hitos en su devenir, posicionamientos ideológicos, pujas dirigenciales y redes de pertenencia, entre otras dimensiones de análisis.

\section{Origen del Partido Bloquista y principales medidas populistas}

En torno al proyecto vitivinícola y procesos de democratización política de comienzos del siglo XX, los hermanos Federico y Aldo Cantoni fundaron el Partido Bloquista (PB) en San Juan, que nació en 1918 como una escisión de la Unión Cívica Radical (UCR). Signado por fuertes confrontaciones con el entonces Gobierno Nacional, el también llamado partido "cantonista" se constituyó en una de las fuerzas provinciales más trascendentes del país. Durante sus primeros años, este partido promovió importantes medidas de corte progresista que, al decir de Pereyra y Vasini (1994), lo convirtieron en una suerte de populismo autóctono: jornada laboral de 8 horas, salario mínimo, seguro por vejez y voto femenino, medidas hasta entonces inéditas en el país.

\section{Alternancia del bloquismo y justicialismo entre dictaduras y democracias}

Con la llegada de Juan Domingo Perón a la Presidencia en 1946 el PB se disolvió, pero tras el golpe de Estado que lo derrocó en 1955, retomó su influencia provincial, articulándose con gobiernos militares y partidos conservadores. Su resurgimiento fue impulsado por Leopoldo Bravo, un líder político que supo concentrar la toma de decisiones y acrecentar su poder durante los años 70 y los 80 . Su particular manejo de los estamentos políticos basado en una autoridad con capacidad de 
consenso con la nación e interacción con las bases partidarias, permite trazar líneas de semejanza con otros líderes posteriores como José Luis Gioja, aunque desde vertientes ideológicas diferentes.

Bravo fue consagrado como conductor del bloquismo y varias veces fue gobernador, tanto por voto popular como por designaciones directas de los gobiernos militares. Según Goldberg et al. (2007), la presencia y accionar del bloquismo en San Juan fue tal que relativizó el peso subnacional del justicialismo, que pudo acceder al gobierno solo en 1973 de la mano de Eloy Camus. Durante este breve periodo, Bravo se desempeñó como senador nacional, ocupando la banca hasta el golpe militar de 1976 cuando el justicialismo fue nuevamente desplazado y el PB arremetió una vez más en el escenario político. En esta ocasión, Bravo fue designado embajador en la URSS y después en Italia. Finalmente, luego de que otros referentes de su partido se alternaran en el poder, fue puesto por la dictadura al frente de la gobernación en 1982.

\section{Inestabilidad política entre la recuperación democrática y el "sanjuaninazo"}

Durante las elecciones de 1983 el PB alcanzó una vez más la gobernación de la provincia, imponiéndose la fórmula Bravo-Ruiz Aguilar con casi el $40 \%$ de los votos. Recién hacia 1989, con la llegada de Menem al gobierno nacional y la aparición de otra fuerza regional (la Cruzada Renovadora - CR-, partido derivado del desarrollismo) cambió la correlación de fuerzas a nivel subnacional. En las elecciones de 1991 el electorado sanjuanino quedó fraccionado casi en tres partes iguales entre la CR, el PB y el PJ, logrando imponerse este último luego de varias disputas internas. En este marco asumió la gobernación el empresario Jorge Escobar, alineado desde su campaña electoral con el programa político-económico promovido por el entonces presidente Menem y su ministro de Economía, Domingo Cavallo.

El estrecho margen de votos por el que se impuso Escobar se tradujo en una posición política débil incluso dentro de su partido. Sumados a la poca aceptación de los diputados del propio PJ, salieron a la luz graves hechos de corrupción que provocaron su destitución vía juicio político a un año de haber asumido. No obstante, Escobar fue finalmente restituido en su cargo mediante un fallo de la Corte Suprema de Justicia y, de hecho, resultó reelecto en 1995, debido fundamentalmen- 
te al apoyo del gobierno nacional, las debilidades y desaciertos del entonces vicegobernador Rojas y la popularidad ganada como "víctima" del juicio político operado (Rodrigo, 2018).

Queda por destacar que la crisis fiscal y medidas de ajuste estructural (rebaja salarial, emisión de bonos y plan de retiros voluntarios) impulsadas por Escobar en sintonía con el programa neoliberal de Menem, provocaron en San Juan un fuerte movimiento de protesta social conocido como "sanjuaninazo", que incluyó entre julio-agosto de 1995 toma de ministerios, huelgas generales y hasta saqueos (Ruffa y López, 2005). Hacia 1999 Escobar volvió a presentarse como candidato a gobernador pero, aunque superó el $43 \%$ de los votos, no pudo derrotar la compleja alianza electoral encabezada por Alfredo Avelín que reunió en una misma coalición a diferentes fuerzas políticas: radicalismo, CR, bloquismo y el Frente País Solidario (FREPASO), que articuló parte importante de la militancia y votos de los sectores centro-izquierda. No obstante, dada la heterogeneidad de la alianza gobernante y sus conflictos internos, sumado a los efectos sociales y económicos de la crisis estructural nacional del 2001-2002 (traducidos en retenciones de sueldos y endeble funcionamiento de áreas como salud y educación), devino una nueva pueblada que terminó también en la destitución del gobernador Avelín².

\section{Reorganización del escenario político y etapa de estabilidad giojista}

Luego de un complejo periodo de interrupciones de mandatos gubernamentales y estallido social, de la mano de Néstor Kirchner se inició un período de reacomodamiento político a escala nacional donde el peronismo asumió un rol protagónico-hegemónico. En San Juan, tras el fallido gobierno aliancista, la destitución de Avelín y la transición que encabezó Wbaldino Acosta (2002-2003) emergió y se consolidó el Frente Para la Victoria (FPV), coalición electoral vinculada al naciente kirchnerismo. En las elecciones a gobernador de 2003, el FPV sanjua-

2 Nancy Avelín y Alfredo Avelín Nollens, hijos del exgobernador Avelín, son a la fecha los líderes principales de la CR y, como tales, han participado en diversas contiendas electorales de la provincia. 
nino fue encabezado por José Luis Gioja ${ }^{3}$, quien obtuvo el $38 \%$ de los votos y alcanzó el gobierno de la provincia manteniéndose en el poder hasta fines de 2015.

La gobernabilidad de Gioja se extendió durante tres períodos consecutivos, cristalizando un período de estabilidad política hasta entonces desconocido en San Juan (Rodrigo, 2019). No obstante, en octubre de 2013 debió alejarse del gobierno a consecuencia de los 119 días de licencia médica e internación que afrontó luego del accidente en helicóptero sufrido y que se cobró la vida de la entonces diputada Margarita Ferrá de Bartol. Durante este interregno, el vicegobernador Sergio Uñac quedó al frente del Ejecutivo y su perfil comenzó a cobrar relevancia política.

Cabe destacar que fue mediante una consulta popular realizada en 2011 cuando Gioja obtuvo el 65\% de apoyo de los sanjuaninos para reformar la Constitución Provincial y habilitar la posibilidad de presentarse a un tercer mandato consecutivo (La Nación, 2011). Durante su gobierno, el PJ retuvo la intendencia de los principales distritos políticos de la provincia: Capital y Rawson. En el primer caso el intendente fue Marcelo Lima y en el segundo su hermano Juan Carlos Gioja.

\section{Ascenso de Uñac y trazos recientes del escenario político sanjuanino}

Pese a que el entonces principal referente provincial del PJ, José Luis Gioja, estaba imposibilitado de competir por un cuarto mandato consecutivo, el oficialismo logró retener una vez más la gobernación durante las elecciones del 2015. En el marco de un contexto nacional signado por el ascenso de Mauricio Macri y la alianza Cambiemos al poder, que implicó un cambio de color político en varias provincias

3 José Luis Gioja es un militante peronista de larga trayectoria en San Juan. Fue colaborador de Eloy Camus durante su gobierno en 1973 y detenido por motivos políticos durante la última dictadura militar. Resultó electo diputado provincial en 1987 y, desde entonces, ha ocupado diversos cargos públicos y partidarios, constituyéndose en uno de los máximos referentes del peronismo sanjuanino. Se ha desempeñado como presidente provisional de la Cámara de Senadores y primer funcionario en la línea sucesoria presidencial de acuerdo con la Ley de Acefalía, quedando a cargo de la presidencia durante dos breves periodos entre 2002-2003. En cuanto a su largo ciclo como mandatario provincial, coincidió casi completamente con los del FPV a nivel nacional (2003-2015). Sobre su biografía, avatares durante la última dictadura y gestión al frente del Ejecutivo Provincial, ver Algañaraz y González (2016) y Rodrigo (2019). 
(entre ellas Buenos Aires), en San Juan el PJ se impuso holgadamente, aunque por una diferencia de votos menor en comparación con los márgenes de victoria con los que el propio Gioja se consagró tres veces al frente del Ejecutivo.

En efecto, durante las elecciones a gobernador del 2015 el FPV sanjuanino resultó triunfante una vez más, obteniendo el 53\% de los votos totales mediante la fórmula encabezada por Sergio Uñac ${ }^{4}$-Marcelo Lima, uno intendente de Pocito y el otro de Capital y ambos exvicegobernadores de Gioja. En la oposición se destacó la alianza Compromiso con San Juan (CSJ), conformada por el Partido Producción y Trabajo, fundado por Roberto Basualdo (exdiputado y senador nacional), junto con el entonces Frente Renovador conducido por Sergio Massa a nivel nacional, cuya fórmula para gobernador fue encabezada, precisamente, por Basualdo y Enrique Conti ${ }^{5}$, quienes superaron el $30 \%$ de los votos.

De lo antedicho puede concluirse, fundamentalmente, que el justicialismo sanjuanino (en tanto fuerza política multinivel) ha logrado hegemonía y gobernabilidad en décadas recientes en gran medida por los acuerdos entablados con fuerzas provinciales tradicionales como el PB y dado el alto grado de aceptación social del que goza el exgobernador Gioja en la provincia y también su reconocimiento político a nivel nacional; constituyendo importantes cuotas de capital simbólico

4 En la trayectoria de Sergio Uñac, se destaca su militancia en la Juventud Universitaria Peronista tras su paso por la Universidad Nacional de Córdoba para formarse como abogado. Pero su incursión en el peronismo está enlazada directamente a su vida familiar. Su padre, Joaquín Uñac, fue intendente del Departamento Pocito durante dos mandatos sucesivos: 1995-1999 y 1999-2003. Durante este período, Sergio Uñac cumplió allí funciones como asesor y en 2003 sucedió a su padre como jefe comunal también por dos períodos consecutivos: 2003-2007 y 2007-2011. Entonces, resultó elegido como compañero de fórmula por José Luis Gioja, desempeñándose como vicegobernador de la provincia entre 2011-2014 y debiendo reemplazarlo en la gobernación desde su accidente aéreo hasta el final del mandato. Finalmente, se consagró como gobernador en las elecciones del 2015. Ver más en Diario Perfil (2019).

5 Roberto Basualdo tiene una larga trayectoria como empresario y político sanjuanino. Por muchos años ha sido el máximo exponente de la oposición al justicialismo. En 2007, compitió contra Gioja tomando como eje de su campaña la situación de la provincia respecto de la minería a cielo abierto. En cuanto a Enrique Conti, ha sido intendente de la Capital y uno de los principales referentes de la oposición. Si bien pertenece al PB, se identifica con una línea "disidente" y opositora a la de Graciela Caselles, actual líder del partido, pero aliada desde 2007 al FPV sanjuanino en carácter de diputada nacional. Ver más en Puente (2017). 
que más recientemente han sido capitalizadas por el actual gobernador Uñac.

\section{Conformación y dinámica de las coaliciones político-partida- rias en San Juan}

En esta sección del artículo se describe el proceso de emergencia de las coaliciones político-partidarias en San Juan, enfatizando en la descripción de las interacciones políticas que involucraron distintos tipos de actores y escalas de participación.

En 2019, el electorado sanjuanino eligió nuevamente representantes para los Poderes Ejecutivo y Legislativo en las escalas provincial y nacional. Pero en esta ocasión se presentó un escenario inusual: los gobiernos nacional y subnacional competían con colores políticos diferentes. En efecto, las riendas del Ejecutivo Nacional las detentaba Cambiemos, coalición liderada por el entonces presidente Mauricio Macri, que interrumpió la gestión continuada que había logrado el kirchnerismo entre 2003-2015; mientras que en San Juan se mantuvo al frente del Ejecutivo el PJ Provincial. Estos factores cristalizaron en la nueva contienda electoral, donde hubo un claro común denominador entre el oficialismo y la oposición provinciales: sortear los pesos y contrapesos de la competencia nacional.

Estratégicamente, el oficialismo de San Juan decidió desdoblar (desvincular) la competencia provincial donde se auguraba una reelección, respecto de la nacional, donde la imagen de Macri gozaba de una mayor aceptación social que hacia el final de su mandato y la acentuada heterogeneidad del peronismo/kirchnerismo parecía no encontrar un rumbo de unidad para enfrentarlo. De acuerdo con Oliveros y Scherlis (2004), el adelantamiento de los procesos electorales resulta siempre una herramienta poderosa en manos de los gobiernos provinciales para tomar distancia de una campaña proselitista dominada por la agenda nacional y asegurarse así una mejor performance en las urnas. Sobre el adelantamiento de las elecciones provinciales, el entonces ministro de gobierno Emilio Baistrocchi (devenido luego en candidato a jefe comunal por el departamento Capital), señaló que:

Es necesario discutir los temas y las problemáticas de San Juan sin intervención de lo que pueda suceder en el ámbito nacional. La realidad de la provincia es diferente a la difícil situación que atra- 
viesa la nación y, por eso, nos parece bueno tener una definición temprana de autoridades que dé margen de certidumbre a la población. (Clarín, 2018).

En consecuencia, y conforme a las normativas vigentes, el calendario electoral provincial previó cuatro instancias de participación ciudadana, dos nacionales y dos subnacionales:

- Elecciones a nivel provincial, para elegir gobernador y vicegobernador, intendentes y concejales municipales, diputados proporcionales y departamentales: a) Elecciones $\mathrm{PASO}^{6}$ el 31 de marzo de 2019; y b) Elecciones Generales el 2 de junio de 2019.

- Elecciones a nivel nacional, para elegir presidente, vicepresidente y diputados nacionales: a) Elecciones PASO el 11 de agosto de 2019; y b) Elecciones nacionales el 27 de octubre de 2019.

Mediante el Decreto Nº 1979/18, el Gobierno de San Juan convocó al proceso eleccionario 2019, abriendo la puerta al (re)armado de las diferentes coaliciones políticas. Según Ferrari (2017), toda coalición electoral implica siempre una alianza entre partidos, fracciones de partidos o grupos de identidad propia, que unen recursos materiales y simbólicos, a la vez que definen candidatos consensuados luego de arduas negociaciones entre sus líderes, en pos de resultar competitivos para el escenario electoral y, en caso de obtener cuotas de poder, distribuirse los beneficios traducidos en espacios de gestión.

No obstante, el proceso de selección/construcción de toda candidatura política implica siempre una etapa de negociaciones, una suerte de "elección antes de la elección" (Field y Siavelis, 2009). Se trata de un complejo interregno de cooperación y competencia intra y extrapartidaria que para quienes resulten nominados supondrá, por un lado, la posibilidad de ascender y representar los intereses de su fuerza política o en su defecto perder cuotas de poder, apoyos y dejar de controlar ciertos recursos y, por otro, sobre ellos recaerá el éxito o la

6 Conforme a la Ley N. ${ }^{\circ}$ 26571/09, se implementó en Argentina un sistema de elecciones Primarias, Abiertas, Simultáneas y Obligatorias (conocidas como PASO), orientadas a determinar qué partidos políticos están habilitados para presentarse en las Elecciones Generales. Cada agrupación podrá presentar una o más líneas internas y aquella que obtenga la mayoría de los votos válidamente emitidos en el distrito y categoría de que se trate participará de la contienda general. 
derrota electoral con todo lo que implica. $\mathrm{Al}$ respecto, examinaremos la dinámica interna y los liderazgos en pugna en las principales coaliciones políticas que participaron de las elecciones 2019 en San Juan:

\section{Devenir del Frente Todos y contrastes por el control político del oficialismo provincial}

En la contienda electoral sanjuanina, fue específicamente el PJ el que más dificultades iniciales presentó para alcanzar acuerdos. Si bien en 2015, el ahora diputado nacional José Luis Gioja pudo/supo imponer a Marcelo Lima, uno de sus hombres de mayor confianza, como vicegobernador de Uñac, logrando instalar consecuentemente a casi la mitad de la Legislatura, con el correr del tiempo el ahora gobernador Sergio Uñac se consolidó en el territorio provincial, y desde algunos sectores especularon incluso con que podría jugar en el horizonte nacional.

En los últimos años, el diálogo entre ambos referentes se ha visto dilatado por las gestiones de cada uno en sus respectivos ámbitos, subnacional y nacional. A ello se suma el relativo desgaste intrapartidario de la figura de Gioja, que se desempeñó como gobernador de la provincia durante tres mandatos consecutivos (de 2003 a 2015) y el acceso al poder de la nueva planta administrativa de gobierno definida en gran medida por el mismo Uñac. El acceso de nuevos referentes a espacios cruciales de la toma de decisiones, como los casos de Emilio Baistrocchi (que asumió como ministro de gobierno) y de Roberto Gattoni (que quedó al frente del Ministerio de Hacienda y Finanzas) hizo que la aguja política del peronismo local se moviera relativamente desde el giojismo al uñaquismo. El perfil de Uñac contrasta con el de su predecesor, no tanto por sus diferencias de edad ( 49 y 70 años, respectivamente), sino más bien por su impronta moderna y tecnocrática de gobierno.

Otro punto de contraste se vincula con las elecciones legislativas del 2017, cuando el gobernador Uñac impulsó el Frente Todos, una nueva coalición electoral que denotó el punto final para la coalición política Frente para la Victoria (FPV) que en 2003 condujo a Néstor Kirchner a la presidencia y específicamente a Gioja a la gobernación de San Juan. Sin embargo, aunque se especuló con que Gioja presentaría su postulación a senador nacional por un frente electoral alternativo al definido por Sergio Uñac (que ya había proclamado la candidatura de su hermano Rubén para encabezar la lista de cargos a senadores), 
finalmente anunciaron la articulación de sus espacios. "Voy a trabajar para la unidad del peronismo sanjuanino, sin apetencias políticas personales y privilegiando la unidad", afirmó Gioja en aquella ocasión ( $\mathrm{La}$ Política on line, 2017).

Asentado en este nuevo frente electoral, Uñac logró consagrar su liderazgo político en la provincia, imponiendo su sello personal al renovado PJ y revitalizando la administración pública a partir de desplazar varios funcionarios afines al giojismo. No obstante, debió realizar una serie de concesiones para mantener la unidad del partido: nombró al exsenador y activo referente kirchnerista Ruperto Godoy en el directorio del Banco San Juan y en ocasión de las mencionadas elecciones legislativas de 2017 incluyó en la lista de diputados a Daniela Castro, adherente a la línea de Gioja.

Respecto de los vínculos con el justicialismo nacional, Gioja se viene desempeñado como titular del PJ en esa escala política desde el 2016, y desde la primera hora se ha mostrado cercano a la expresidenta y entonces senadora Cristina Fernández de Kirchner. Uñac, en cambio, ha mantenido una distancia prudente de los distintos conflictos intraperonistas, entablando buen diálogo con referentes kirchneristas como el diputado nacional Agustín Rossi, el propio Sergio Massa y el amplio abanico de los entonces gobernadores peronistas, entre ellos Juan Schiaretti.

No obstante, en todas sus alocuciones públicas tanto Gioja como Uñac han coincidido en que la mejor opción para la provincia, y para el PJ en particular, era alcanzar la unidad. El 10 de enero de 2019 fue una fecha clave al respecto, pues venció el plazo para la presentación de los frentes y alianzas que competirían en las Elecciones PASO y Generales de San Juan. Así, en medio de un contexto nacional en el que el peronismo todavía no lograba concertar la unidad, todo el PJ provincial se erigió nuevamente detrás del Frente Todos, aglutinando una vez más diferentes espacios. Este frente programático fue el más numeroso de todos los que se presentaron en la contienda electoral, pues sumó más de 40 integrantes entre partidos políticos y organizaciones/movimientos sociales que no contaban con personería jurídica. Además, en comparación con las elecciones legislativas del 2017 dicha coalición pasó de articular 8 a 15 fuerzas políticas y de 11 a 33 agrupaciones y movimientos sociales adherentes. 
Integrado por el PJ como columna vertebral, se sumaron al Frente Todos: el bloquismo de Graciela Caselles; el Partido Conservador Popular; el Partido Unidad y Progreso; el Partido Frente Grande; el Partido Popular Participativo de la exintendenta de Rivadavia Ana María López; el Partido Movimiento, Integración y Desarrollo (MID); el Partido Municipal Crecimiento Económico y Equilibrio Republicano (CRECER) del intendente de San Martín Cristian Andino; el Partido Compromiso Social; el Partido Municipal Movimiento Popular del Este del exjefe comunal de Caucete Emilio Mendoza; el Partido Convicción Federal (CONFE) de Mauricio Ibarra, exintendente de Rawson; entre varios otros. Respecto de los movimientos sociales que lo integraron se cuentan: el Evita, Martín Fierro y Virgen de Fátima, además de varias agrupaciones kirchneristas cuya máxima referente provincial es Marita Benavente, que fue candidata a vicegobernadora de la provincia en la interna del PJ durante las elecciones 2015 (Diario de Cuyo, 2019a).

Ahora bien, lograr la unidad del PJ (y saldar el relativo quiebre político entre Uñac y Gioja), sumando nuevas adhesiones al Frente Todos fue solo el comienzo. Aún restaba lograr la integración de las listas y definir las candidaturas municipales. El proceso de selección de candidatos que precedió a las campañas electorales implicó el despliegue de variadas estrategias políticas y la inversión de importantes cuotas de capital social. Si bien el gobernador Uñac fue el principal orquestador del elenco político-partidario del Frente Todos, desempeñando un rol fundamental como traccionador de la campaña provincial y en algunos municipios, no en todos los casos primaron fórmulas de consenso, deviniendo disputas con referentes y grupos de apoyo giojistas, optando finalmente por dirimir las candidaturas mediante las elecciones PASO.

Como vimos, esta provincia presenta una gran concentración demográfica en los cinco departamentos del Gran San Juan, los que inciden fuertemente en las elecciones. El distrito de mayor peso político es Rawson y al momento de la nueva contienda estaba gobernado por Juan Carlos Gioja (hermano de José Luis), que no podía ser reelecto. La estrategia del giojismo fue impulsar un nuevo precandidato: el hasta entonces secretario de Obras Rubén García. En cuanto al uñaquismo, propugnó un precandidato propio: el diputado departamental Pablo García Nieto, produciéndose así un intenso cruce entre dos fuerzas del mismo partido en un distrito fundamental de la provincia. 
Otro distrito clave para las elecciones lo constituye la Capital de San Juan, donde se esgrimió un cuadro antagónico entre el entonces intendente, Franco Aranda, que buscaba renovar su mandato, y un importante referente de la gestión uñaquista, el ministro de gobierno Emilio Baistrocchi. Si bien esta disputa guarda similitud con el caso de Rawson, es menester destacar dos elementos importantes: la imagen de Aranda se vio desgastada para la opinión pública tras la controvertida remodelación implementada en la peatonal céntrica de la provincia (Diario de Cuyo, 2018) y; por otro lado, la visibilización del gobernador Uñac en el distrito (cuyo apoyo político fue virando sutilmente hacia Baistrocchi) fue un factor clave en la contienda, a diferencia de Rawson que conto con un Gioja muy activo en campaña. En el departamento Rivadavia se produjo también un escenario particular, al postularse tres precandidatos del Frente Todos: Marcelo Delgado, Raúl Alonso y Ruperto Godoy, cuyo común denominador fue recurrir a la figura del Uñac para obtener cierto efecto de arrastre en el desarrollo de sus campañas, incluyendo actos partidarios con la participación de los tres en simultáneo. Se trató de una propuesta compartida que poco dejó percibir a cada uno de ellos individualmente.

En los otros dos departamentos céntricos, no hubo contienda interna del Frente Todos durante las PASO: tanto Fabián Gramajo - que venía de una buena gestión en Chimbas y ahora buscaba su reelección-, como el funcionario Lucio González que aspiraba a recuperar el departamento de Santa Lucía para el justicialismo (entonces gobernado por el nuevo líder de la oposición, Marcelo Orrego), pudieron consolidar sus candidaturas sin sobresaltos. No obstante, hubo otros distritos electorales más alejados de la zona urbana, donde Uñac debió recurrir también a las urnas para definir candidatos: 9 de julio, Angaco, Zonda y Caucete. En este sentido, el espíritu democrático del gobernador de San Juan cristalizó en el traslado de las aspiraciones individuales de figuras políticas relevantes a las urnas, y que la decisión popular fuera la que determinara los candidatos.

\section{Reperfilamiento de coaliciones opositoras y conformación del Frente Con Vos}

En elecciones previas, la principal oposición al gobierno justicialista estuvo encabezada por el Senador Nacional Roberto Basualdo, un aspirante histórico a la gobernación de San Juan que fue candida- 
to en varias oportunidades enfrentando a Gioja. De hecho, en 2015 su partido Producción y Trabajo trazó una alianza electoral con el Frente Renovador de Massa y conformó la mencionada Alianza CSJ, cuya fórmula gubernamental encabezó el mismo Basualdo. En aquella ocasión, bajo el paraguas de Cambiemos la UCR sanjuanina conformó un frente electoral propio, con adherentes del partido Dignidad Ciudadana y referentes locales del PRO (Propuesta Republicana) encabezados por Eduardo Cáceres y Martín Turcumán, bajo la denominación Juntos por San Juan. Pero ahora, los efectos de la tan anunciada polarización del escenario político nacional entre el macrismo y peronismo/kirchnerismo - sumado a las indefiniciones de otros líderes peronistas que aspiraban alcanzar la Presidencia-, provocó un fuerte movimiento político en el amplio arco de la oposición provincial.

El creciente malestar económico-social por el que entonces atravesaba el país, asociado a la gestión de Cambiemos a nivel nacional, conllevó a que la principal coalición opositora provincial vinculada con dicha línea política optara por reinventar su imagen. Frente Con Vos, fue el nombre de la nueva alianza electoral conformada por: el partido Producción y Trabajo de Basualdo; el PRO; Acción Ciudadana Transformadora Única de Renovación (ACTUAR); la UCR; el bloquismo disidente y partidos departamentales de Caucete y 9 de julio. El otrora principal candidato de la oposición Roberto Basualdo, optó por relegar sus aspiraciones políticas en favor de Marcelo Orrego, intendente saliente de Santa Lucía con alta aceptación social. Una de las principales estrategias políticas de esta coalición fue despegarse de la debilitada figura del líder nacional de Cambiemos, Mauricio Macri, y desarrollar una campaña netamente en el territorio local y provincial con candidatos sin proyección nacional. El mismo Orrego así lo había expresado: "no va a ser necesaria la presencia en San Juan de figuras del gobierno nacional" y "no tengo compromiso de ningún tipo con fuerzas nacionales, mi único compromiso es con la gente" (La Nación, 2019).

Martín Turcumán, fue otro de los aspirantes más destacados a la gobernación de San Juan. Esta vez, ofició como principal referente del llamado Frente San Juan Primero, conformado por: Acción por Una Democracia Nueva (ADN); Partido Socialista, Movimiento Libres del Sur; Fuerza para la Unidad y el Cambio Inclusivo (FUCI); Federalismo 
Organizado de Jóvenes en Acción (FORJA) y partidos departamentales de Santa Lucía y Zonda.

A estas tres coaliciones políticas, se sumaron cinco partidos que compitieron solos durante la contienda electoral: la Nueva Izquierda cuya precandidata a la gobernación fue Mary Garrido; el Partido del Trabajo y del Pueblo (PTP) encabezado por Alberto Agüero; la Nueva Dirigencia liderada por Marcelo Tejada; la Cruzada Renovadora encabezada por Nancy Avelín (hija del exgobernador); y finalmente Dignidad Ciudadana que, a diferencia del 2015 donde jugó en sociedad con Cambiemos, ahora optó por desvincularse siendo Gustavo Fernández su precandidato a gobernador.

En suma, las Elecciones PASO provinciales evidenciaron una oposición renovada con fuertes actores políticos emanados de la gestión municipal y otras figuras de peso, como Roberto Basualdo, desempeñando un rol anejo. No obstante, la principal alianza opositora, el Frente Con Vos (ex-Cambiemos), perdió en el transcurso de la contienda electoral 2015 a la 2019, dos socios importantes como Dignidad Ciudadana y la Cruzada Renovadora, cuyos aportes en números electorales si bien no hubieran alcanzado para emparentar al Frente Todos, habrían contribuido a disputar cargos de diputados proporcionales y concejales en los municipios. La Tabla 1, muestra las precandidaturas a la gobernación de San Juan según fuerzas electorales.

Tabla 1

Candidatos a la gobernación de San Juan según frentes o partidos. Elecciones 2019

\begin{tabular}{lll}
\hline Frente o partido político & $\begin{array}{l}\text { Candidatos a } \\
\text { gobernador }\end{array}$ & $\begin{array}{l}\text { Candidatos a } \\
\text { vicegobernador }\end{array}$ \\
\hline Frente Todos & Sergio Uñac & Roberto Gattoni \\
\hline Frente Con Vos & Marcelo Orrego & Susana Laciar \\
\hline Frente San Juan Primero & Martín Turcuman & Conrado Suárez Jofré \\
\hline Partido Cruzada Renovadora & Nancy Avelín & Jorge Alanís \\
\hline Partido Dignidad Ciudadana & Gustavo Fernández & Federica Mariconda \\
\hline Partido Nueva Dirigencia & Marcelo Tejada & María Roca \\
\hline Partido del Trabajo y del Pueblo & Alberto Agüero & Claudia Liquitay \\
\hline Partido Nueva Izquierda & Mary Garrido & Nanci Avaro \\
\hline
\end{tabular}

Fuente: Elaboración propia sobre la base de datos del Tribunal Electoral de San Juan (2019). 


\section{Análisis de resultados electorales y reconfiguración del esce- nario político provincial}

El complejo proceso de negociación, construcción y legitimación de la oferta político-partidaria que antecede a toda contienda electoral finaliza con los escrutinios y abre paso a una etapa, también compleja, de reconfiguración del escenario político. En esta sección del trabajo examinaremos, precisamente, las cifras finales/definitivas de las elecciones 2019 en San Juan.

\section{Elecciones PASO y Generales Provinciales}

El 31 de marzo de 2019 se celebraron las Elecciones PASO en San Juan para cubrir los cargos a gobernador, diputados provinciales y departamentales, intendentes y concejales ${ }^{7}$. Ninguno de los ocho frentes/ partidos que participaron de la contienda, postularon más de una lista para los cargos en juego, salvo en la categoría intendentes, donde las tres coaliciones políticas (Frente Todos, Con Vos y San Juan Primero) presentaron dos listados, cada uno en varios departamentos, dirimiendo sus internas en las urnas. A continuación, en la Tabla 2 se detallan los resultados finales en cada categoría.

$7 \quad$ Un aspecto relevante para tener en cuenta es que San Juan se organiza en torno a 19 departamentos que constituyen distritos electorales únicos sobre los que se asientan los respectivos poderes municipales. Los mismos se agrupan en diferentes categorías políticas según la cantidad de habitantes estimada por el último Censo Nacional. El artículo $\mathrm{N}^{\circ} 240$ de la Constitución Provincial, ha fijado el criterio de tal clasificación: de "primera categoría" son aquellas ciudades que cuentan con más de 30.000 habitantes, de "segunda" aquellas con más de 10.000 y de "tercera" las que superen los 2.000 habitantes. En efecto, los departamentos asentados en el llamado "Gran San Juan” (principal cordón urbano-económico de la provincia) constituyen los distritos más relevantes en cada competencia política. Según estimaciones del Tribunal Electoral Provincial (2019), los departamentos Rawson y Capital aglutinaron en la última contienda la mayor cantidad de electores, superando los 90 mil cada uno. Se ubican luego Rivadavia y Chimbas con más de 60 mil; y con poco más de 40 mil se destacan Pocito y Santa Lucía. Debajo de los 30 mil ciudadanos en condiciones de votar se ubican los 13 departamentos restantes asentados fuera del "Gran San Juan". 
Tabla 2

Cantidad de votos a gobernador y diputados, según frente/partido político. Elecciones PASO. San Juan, año 2019

\begin{tabular}{lll}
\hline Frente o partido político & Gobernador & $\begin{array}{l}\text { Diputados } \\
\text { provinciales }\end{array}$ \\
\hline Frente Todos & 220.102 & 214.167 \\
\hline Frente Con Vos & 127.396 & 121.771 \\
\hline Frente San Juan Primero & 17.019 & 17.796 \\
\hline Partido Cruzada Renovadora & 8.622 & 8.318 \\
\hline Partido Dignidad Ciudadana & 4.011 & 4.002 \\
\hline Partido Nueva Dirigencia & 4.839 & 4.899 \\
\hline Partido del Trabajo y del Pueblo & 5.686 & 5.868 \\
\hline Partido Nueva Izquierda & 7.504 & 8.034 \\
\hline Total electores & 395.179 & 384.855 \\
\hline
\end{tabular}

Fuente: Elaboración propia en base a datos del Observatorio Político Electoral (2019).

Como puede observarse, Sergio Uñac del Frente Todos obtuvo la mayoría de los votos a gobernador $(55,7 \%)$ y, en segundo lugar, con el 32,2\% quedó Marcelo Orrego, consolidándose como principal oponente. El tercer puesto, lo ocupó el Frente San Juan Primero liderado por Martín Turcumán con un 4,3\% de votos. Los demás contrincantes obtuvieron entre 4.000 y 8.000 sufragios. Se evidenció, así, una gran concentración de votantes entre las primeras dos coaliciones políticas que conjuntamente reunieron más del $80 \%$ del electorado provincial. En cuanto a los diputados provinciales, el resultado de las PASO mostró que el corte de boletas no fue un fenómeno acentuado, ya que las cifras marcaron la misma tendencia que la elección de gobernador: un $56 \%$ a favor de los candidatos del Frente Todos y un 32\% a favor del Frente Con Vos. Respecto de la disputa por las intendencias, la Tabla 3 muestra los resultados de cada distrito. 
Tabla 3

Cantidad de Intendencias ganadas por frente/partido político. Elecciones PASO. San Juan, año 2019

\begin{tabular}{lc}
\hline Frente o partido político & Cantidad de intendencias ganadas \\
\hline Frente Todos & 15 \\
\hline Frente Con Vos & 2 \\
\hline Partido Somos Integración & 1 \\
\hline Partido Mejor Nosotros & 1 \\
\hline Frente San Juan Primero & 0 \\
\hline Total & 19 \\
\hline
\end{tabular}

Fuente: Elaboración propia sobre la base de datos del Tribunal Electoral de San Juan (2019).

En la mayoría de los distritos municipales, 15 de 19, se impusieron candidatos del Frente Todos. Dentro del Gran San Juan, el oficialismo embanderado en dicha coalición electoral alcanzó la gobernación de tres departamentos: Capital, Chimbas y Rawson. En cuanto a Rivadavia y Santa Lucía se impusieron Fabián Martín y Juan José Orrego (hermano de Marcelo Orrego) referentes del Frente Con Vos. Otras fuerzas de la oposición se hicieron de los gobiernos municipales de Iglesia y Ullúm: Somos Integración en el primer distrito y Mejor Nosotros en el segundo. Ambos departamentos quedaron en manos de partidos comunales, que se reconocen cercanos al oficialismo provincial y de hecho han mantenido acuerdos previos.

Las Elecciones PASO provinciales mostraron, en suma, un gran apoyo a Uñac y al PJ en la mayoría de los distritos municipales, consolidando sus perspectivas de reelección, materializadas finalmente en las Elecciones Generales del 2 de junio como veremos a continuación. 
Figura 1.

Comparación resultados Elecciones PASO y Generales, categoría gobernador y vicegobernador según frente/partido político. San Juan, año 2019

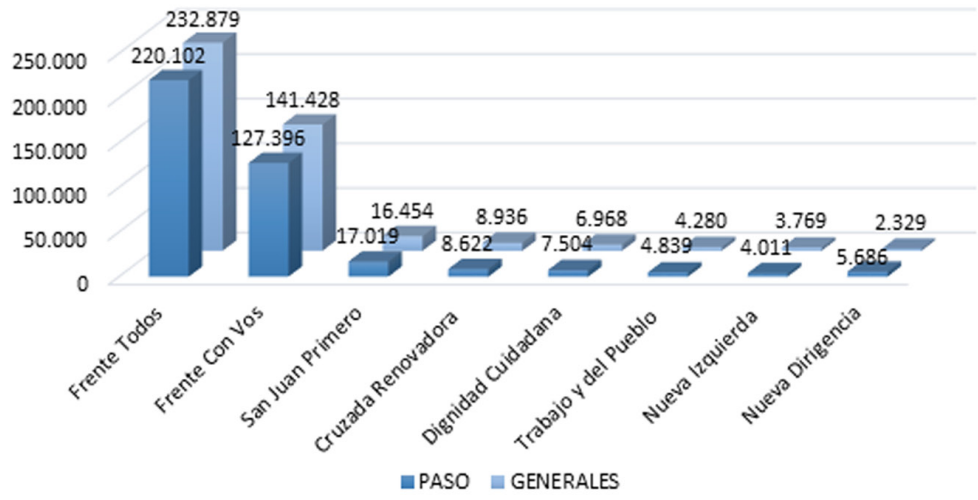

Fuente: Elaboración propia sobre la base de datos del Tribunal Electoral de San Juan (2019).

A partir de la Figura 1, se desprende que las Elecciones Generales corroboraron el poder político alcanzado por Uñac, consagrado finalmente como gobernador de la provincia por segunda vez con una cantidad porcentual de votos afirmativos similar a las PASO (55,8\%). En cuanto a Marcelo Orrego, quedó mejor posicionado que en las primarias, sumando casi dos puntos porcentuales adicionales (33,9\%). Muy atrás quedó el resto de los contendientes: Martín Turcuman (Frente San Juan Primero) retuvo el 4\% de los votos; Nancy Avelín (Cruzada Renovadora) obtuvo un 2\%, similar al de Gustavo Fernández (Dignidad Ciudadana). Respecto de la cantidad de votantes, hubo 21.864 personas más que en la contienda anterior, alcanzando los 417.043 electores efectivos.

En cuanto a diputados, el oficialismo alcanzó 26 de las 36 bancas disponibles, obteniendo una mayoría calificada para aprobar sus eventuales leyes durante la próxima gestión: obtuvo 15 departamentales y 11 proporcionales en total. Por su parte, el Frente Con Vos ubicó ocho diputados y San Juan Primero impuso dos más. En comparación con las elecciones 2015, el Frente Todos resultó mejor posicionado, sumando 15 (de los 19) diputados departamentales e imponiéndose en Caucete, Va- 
lle Fértil, Ullum y Zonda, territorios que en aquella ocasión habían sido conquistados por la oposición. En cuanto a la principal coalición opositora, mantuvo al legislador de Santa Lucía, Carlos Platero, y al de Rivadavia, Sergio Miodowsky. Por su parte, el frente de Martín Turcumán ganó las diputaciones departamentales de Iglesia con Daniel Montaño y Angaco con Marcelo Mallea (Diario de Cuyo, 2019b).

Respecto de la elección de intendentes, si bien el oficialismo se consolidó en la mayoría de los distritos, devinieron algunos reveses entre las PASO y Generales, que es menester destacar.

Tabla 4

Comparación resultados Elecciones PASO y Generales, categoría intendentes, según frente/partido político y cantidad de votos por distrito. San Juan, año 2019

\begin{tabular}{|c|c|c|c|c|}
\hline \multirow{2}{*}{$\begin{array}{l}\text { Distritos } \\
\text { Municipales }\end{array}$} & \multicolumn{2}{|l|}{ Elecciones PASO } & \multicolumn{2}{|c|}{ Elecciones Generales } \\
\hline & $\begin{array}{l}\text { Frente/partido } \\
\text { que se impuso }\end{array}$ & $\begin{array}{l}\text { Cantidad } \\
\text { de votos }\end{array}$ & $\begin{array}{l}\text { Frente/partido } \\
\text { que se impuso }\end{array}$ & $\begin{array}{l}\text { Cantidad } \\
\text { de votos }\end{array}$ \\
\hline Albardón & Frente Todos & 8.239 & Frente Todos & 8.089 \\
\hline Angaco & Frente Todos & 3.599 & $\begin{array}{l}\text { Frente San Juan } \\
\text { Primero }\end{array}$ & 2.724 \\
\hline Calingasta & Frente Todos & 2.845 & Frente Todos & 2.810 \\
\hline Capital & Frente Todos & 34.626 & Frente Todos & 31.441 \\
\hline Caucete & Frente Todos & 14.003 & Frente Todos & 12.441 \\
\hline Chimbas & Frente Todos & 34.548 & Frente Todos & 37.916 \\
\hline Iglesia & $\begin{array}{l}\text { Partido Somos } \\
\text { Integración }\end{array}$ & 2.102 & $\begin{array}{l}\text { Partido Somos } \\
\text { Integración }\end{array}$ & 2.078 \\
\hline Jáchal & Frente Todos & 6.351 & Frente Todos & 6.916 \\
\hline 9 de julio & Frente Todos & 3.693 & Frente Con Vos & 3.786 \\
\hline Pocito & Frente Todos & 19.609 & Frente Todos & 18.818 \\
\hline Rawson & Frente Todos & 39.254 & Frente Todos & 39.339 \\
\hline Rivadavia & Frente Con Vos & 22.190 & Frente Con Vos & 27.441 \\
\hline San Martín & Frente Todos & 4.432 & Frente Todos & 4.925 \\
\hline Santa Lucía & Frente Con Vos & 16.014 & Frente Con Vos & 17.134 \\
\hline Sarmiento & Frente Todos & 5.324 & Frente Todos & 6.395 \\
\hline Ullum & $\begin{array}{l}\text { Partido Mejor } \\
\text { Nosotros }\end{array}$ & 1.412 & $\begin{array}{l}\text { Partido Mejor } \\
\text { Nosotros }\end{array}$ & 1.417 \\
\hline Valle Fértil & Frente Todos & 2.807 & Frente Todos & 2.990 \\
\hline 25 de mayo & Frente Todos & 4.917 & Frente Todos & 5.293 \\
\hline Zonda & Frente Todos & 2.693 & Frente Todos & 2.071 \\
\hline
\end{tabular}

Fuente: Elaboración propia sobre la base de datos del Tribunal Electoral de San Juan (2019). 
La Tabla 4 muestra, por un lado, el efecto de arrastre político del gobernador Uñac a nivel comunal en la mayoría de los departamentos, independientemente de las respectivas cuotas de poder local que pudieron/supieron desplegar sus respectivos jefes municipales. De hecho, se recuperó el distrito de Caucete que desde 2015 estaba en poder de la oposición. Pero, por otro lado, luego del saneamiento político que significaron las Elecciones Primarias, las fuerzas de la oposición lograron reperfilar sus estrategias y terminaron arrebatándole al oficialismo dos distritos que se estimaban ya conquistados: 9 de julio y Angaco. En el primero de los casos, si bien el Frente Todos se impuso en las primarias por sobre el Frente Con Vos, de la mano de Eduardo Banega, sufrió un duro revés en las Elecciones Generales. Gustavo Núñez, jefe comunal y referente de Con Vos logró finalmente retener su mandato y conservar el color político opositor en el departamento con el 53,7\% de los sufragios. En cuanto a Angaco, fue el único departamento en el que triunfó el Frente San Juan Primero con el 45,5\%, consagrándose como intendente Carlos Maza Pezé, luego de una apretada contienda con el Frente Todos que fue respaldado por un $41,8 \%$ del electorado.

Salvo estos dos casos donde la contienda electoral fue muy ajustada, en el resto de los distritos electorales se confirmaron los márgenes de victoria previstos en las PASO. En el Gran San Juan se consagraron Emilio Baistrocchi como intendente de Capital (con más del 48\%); Rubén García en Rawson (con casi el 60\%), ambos del Frente Todos. En cuanto a Rivadavia y Santa Lucía logró consolidarse el Frente Con Vos: Fabián Martín resultó reelecto en el primer caso con el 54\% de los votos y Juan José Orrego en el segundo con el 56,4\%. En cuanto a Chimbas, el tercero de los distritos más poblados de San Juan, fue uno de los escenarios de mayor relevancia. Fabián Gramajo, también candidato del Frente Todos, no solo obtuvo su reelección como jefe comunal, sino que se consagró con el mayor respaldo departamental entre todos los intendentes electos: alcanzó el 76,5\% de los votos. Respecto del resultado de las elecciones, el ahora nuevamente intendente Gramajo ha señalado:

Entre todos los votantes chimberos nosotros hemos obtenido un apoyo de más del $76 \%$. Pero no solo nos han votado los afiliados peronistas en el departamento que son 4.632, nuestro proyecto fue votado por más de 38.000 personas. Pero no me puedo quedar sacando cuentas matemáticas, hay que tomar decisiones. Me quedan 
4 años más de gestión y hay que construir desde abajo hacia arriba con bases sólidas para lograr igualdades, esa ha sido y es la clave. (Gramajo F., comunicación personal, 27/11/2019).

En suma, el Frente Todos se impuso en 13 de los 19 municipios sanjuaninos relegitimando el poder de Uñac, del PJ Provincial y sus aliados. De allí, que el mapa político de la provincia quedara reconfigurado como se muestra en la Figura 2.

Figura 2.

Distritos subprovinciales de San Juan, según frente/partido político triunfante. Elecciones Generales. Año 2019

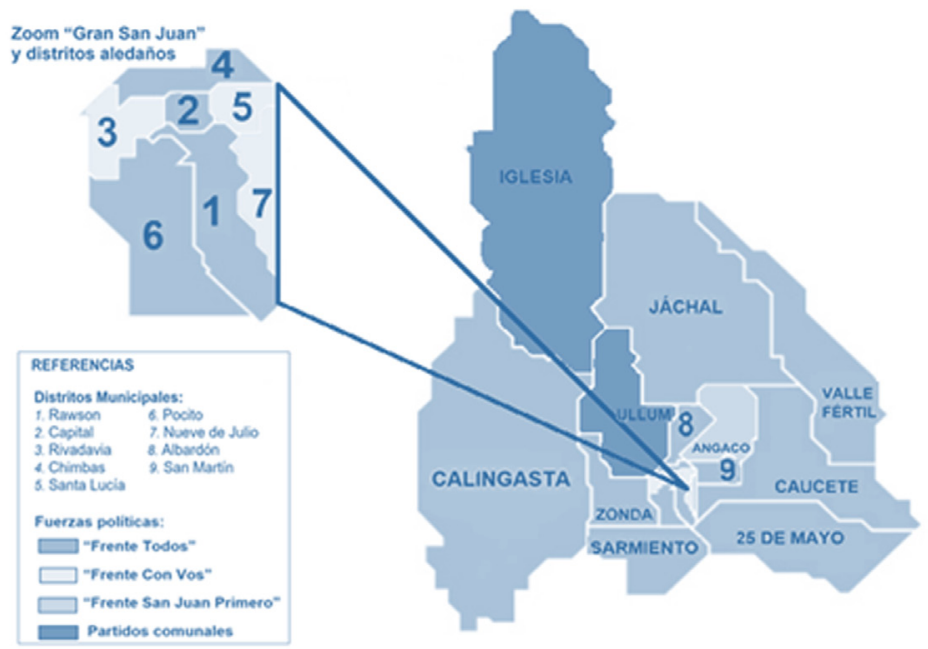

Fuente: Elaboración propia sobre la base de datos del Tribunal Electoral de San Juan (2019).

\section{Elecciones PASO y Generales Nacionales}

En cada contienda electoral, los espacios subnacionales constituyen importantes locus de competencia y legitimación política tanto de coaliciones/partidos como de los políticos mismos, incidiendo no solo a escala provincial y subprovincial, sino también nacional. En el caso de la dinámica electoral instituida durante 2019 en San Juan, devino en un espacio importante de convergencias políticas donde ciertos actores que acumularon/construyeron poder situado, como José Luis Gioja y Sergio Uñac, contribuyeron a reconfigurar el escena- 
rio político subnacional e incidieron relativamente en la trama nacional. Pero veamos los puntos de intersección de la política-partidaria de San Juan con la nacional a partir del rol de estos doble-agentes.

En ocasión de las elecciones nacionales, celebradas en agosto y octubre pasados, Uñac se mantuvo expectante en el debate por la reconstrucción del peronismo a escala nacional. A diferencia de otros gobernadores peronistas, evitó durante un buen tiempo todo tipo de encuentros y acciones que lo visibilizaran en algún espacio particular. Si bien fue uno de los primeros líderes políticos en incentivar la candidatura presidencial de Roberto Lavagna y algunos medios barajaron su nombre como posible compañero de fórmula en Alternativa Federal, coalición nacional que buscaba romper la polarización entre macrismo/kirchnerismo, mantuvo vínculos constantes con varios referentes kirchneristas. De hecho, cuando la expresidenta Cristina Fernández de Kirchner decidió cederle el primer lugar de la nueva fórmula presidencial del PJ a su exjefe de Gabinete Alberto Fernández y ser candidata a la Vicepresidencia, avanzando así hacia la unidad nacional del peronismo, Uñac fue uno de los primeros gobernadores en elogiarla. Específicamente, destacó la "actitud de grandeza de Cristina, deponiendo su interés personal respecto de una construcción global. Acá trabajamos para la construcción nacional de un proyecto que incluya a todos los argentinos y la expresidenta ha dado muestras de ello". (El Destape, 2019).

Sin dudas, Alberto Fernández y Cristina Fernández de Kirchner se convirtieron en los grandes protagonistas de la política nacional argentina en 2019, al conocerse sus precandidaturas a presidente y vicepresidenta de la nación, logrando la casi imposible unidad del peronismo/kirchnerismo. A ello se refirió Gioja en una entrevista:

En el peronismo hay una bandera central que es casi sinónimo de éxito, que es la unidad. Todo el diálogo y consenso que nos faltó en el 2015, ahora lo alcanzamos. Fue inmediatamente después de esa derrota, cuando el peronismo empezó a pensar en un proceso de unidad. La Pampa, Neuquén y San Juan fueron las primeras provincias donde se logró acordar esa unidad y desde el PJ Nacional apoyamos cada uno de esos procesos. Después vino Entre Ríos, Santa Fe y así hasta llegar a la unidad nacional. (Gioja, comunicación personal, 28/12/2019). 
El relato de Gioja evidencia que lo político no es una mera construcción dada de "arriba hacia abajo" como si las provincias fueran simplemente receptoras de directivas, sino que constituyen verdaderos espacios de gestión de lo político. De hecho, durante esta contienda electoral, desde varios medios provinciales y nacionales se señaló muchas veces que el modelo de armado político del peronismo sanjuanino conducido por Uñac, sirvió de plataforma para el armado del modelo político nacional que encabezaba ahora Alberto Fernández. Durante todas sus campañas, Uñac hizo hincapié en la necesidad de alcanzar la unidad política provincial, la cual cristalizó en el armado de las listas al contener a distintos sectores del peronismo local y bregó por un armado nacional similar. Este modelo de unidad fue reconocido y celebrado también por el mismo Alberto Fernández, quien en reiteradas ocasiones señaló que "San Juan ha sido el modelo a seguir. Unidos y respetando la disidencia, vamos a construir la opción que los argentinos reclaman para superar este presente". (Tiempo de San Juan, 2019).

Frente de Todos fue de la denominación de la coalición política nacional que esgrimió la fórmula presidencial Fernández-Fernández, emulando de hecho el nombre del frente electoral sanjuanino (encabezado por Uñac) que entonces ya había triunfado holgadamente en las Elecciones PASO provinciales. Este acuerdo político nacional fue celebrado finalmente entre Alberto Fernández como referente del PJUnidad Ciudadana y Sergio Massa, líder del Frente Renovador. En gran medida, la coalición logró formalizarse por esfuerzos del exgobernador de San Juan, José Luis Gioja, en calidad de presidente del PJ Nacional que, junto a otros referentes de primera línea del peronismo y el kirchnerismo, realizó innumerables gestiones para sumar a Massa y a otros gobernadores peronistas al acuerdo (Clarín, 2019). Respecto de ello, el mismo Gioja ha señalado:

El vínculo de Unidad Ciudadana con el peronismo y el aporte de Massa fueron cruciales. Pero creo que la jugada más importante de todo el proceso fue lanzar la fórmula Fernández-Kirchner y en ese sentido la jugadora más importante, la protagonista de todo este proceso fue ella, Cristina. Ella tuvo la grandeza de ver, como tantas veces lo ha dicho Alberto, que con ella sola no ganábamos, pero sin ella mucho menos. Por suerte, Massa entendió, es un compañero 
muy inteligente. Lo fuimos a ver, comprendió y pudimos sumarlo. Si él hubiese ido por afuera, perdíamos. Fueron todos hechos claves. (Gioja, comunicación personal, 28/12/2019).

La confluencia de Massa y el PJ con el peronismo-kirchnerista en una misma alianza electoral conllevó lógicamente al reperfilamiento de los otros espacios políticos. Además del Frente Todos, entre las diversas coaliciones que participaron de la contienda por la Presidencia de la nación pueden mencionarse: Juntos por el Cambio, Consenso Federal, Frente de Izquierda y de los Trabajadores-Unidad, Unirte por la Libertad y la Dignidad y Frente Nos, entre otros partidos/coaliciones que recibieron menos del 1,5\% de los votos válidos en las Elecciones Primarias y no pudieron pasar a las generales. Entre estas alianzas, la más destacada fue sin dudas Juntos por el Cambio (ex-Cambiemos), esgrimida por el entonces presidente Macri que buscaba su reelección y como estrategia de amplitud y diálogo, optó por sumar a Miguel Ángel Pichetto (un senador nacional del bloque justicialista, pero distante y crítico de Cristina Fernández y el kirchnerismo) como compañero de fórmula.

Ahora bien, el electorado sanjuanino además de elegir presidente y vicepresidente debía renovar tres bancas en la Cámara Baja y seis fuerzas políticas participaron de las elecciones:

- El Frente de Todos presentó una lista de unidad, cuyos principales candidatos fueron precisamente José Luis Gioja y Graciela Caselles (referente del PB y aliada al PJ desde el 2007).

- Juntos por el Cambio (ex-Cambiemos) presentó dos listas: Con Vos liderada por Marcelo Orrego (que si bien perdió frente a Uñac en la contienda provincial, se consagró como máximo referente de la oposición) y Defensores del Cambio, que fue encabezada por Eduardo Castro, presidente de la UCR en San Juan.

- Consenso Federal también presentó dos listas: Concertación y Unidad, encabezadas por Conrado Suárez Jofré y Nancy Avelín, respectivamente.

- El resto de las fuerzas presentaron listas únicas: Marcelo Tejada encabezó el Partido Nueva Dirigencia, Mary Garrido el Frente de la Izquierda y los Trabajadores (FIT) y Gustavo Fernández Dignidad Ciudadana. 
En sintonía con otras regiones del país, las PASO nacionales realizadas el 11 de agosto de 2019 reflejaron una importante concentración de votos en el Frente de Todos y Juntos por el Cambio en la contienda por la Presidencia de la nación. Ello repercutió en la competencia por los cargos a diputados nacionales: Gioja se consolidó como candidato del Frente Todos, en Juntos por el Cambio se impuso Marcelo Orrego, mientras que en Consenso Federal lo hizo Nancy Avelín. El resto de las fuerzas políticas, no logró superar el piso electoral establecido. En cuanto a las Elecciones Generales del 27 de octubre, estas no evidenciaron grandes alteraciones. A continuación, presentamos en la Figura 3 una comparación de los resultados obtenidos en cada instancia electoral.

Figura 3.

Comparación resultados Elecciones PASO y Generales, categoría presidente y vicepresidente. San Juan. Año 2019

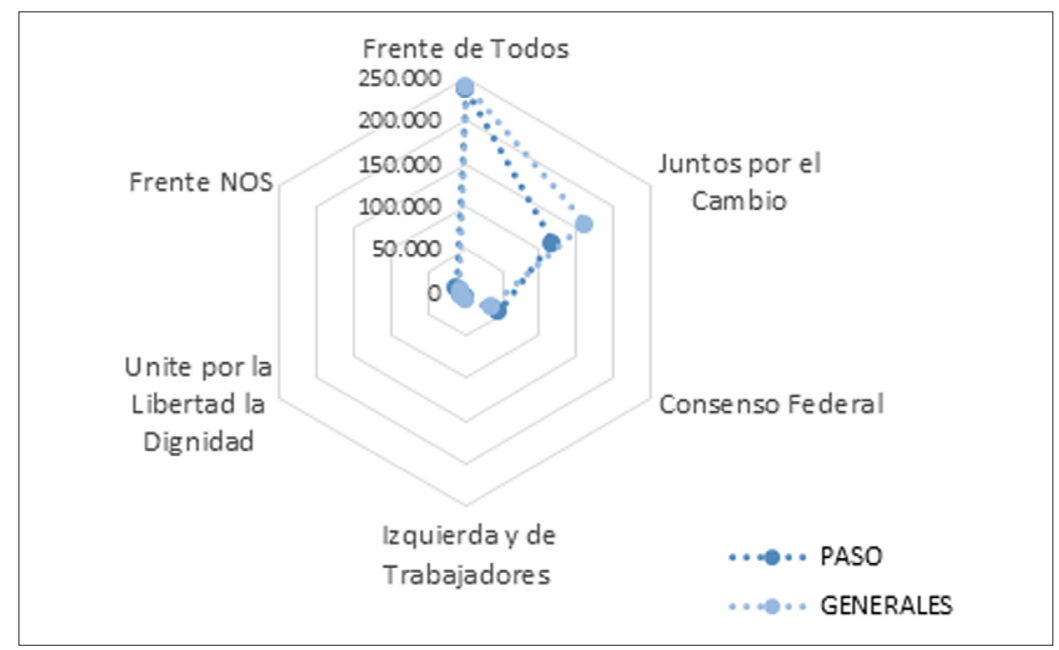

Fuente: Elaboración propia sobre la base de datos del Observatorio Político Electoral (2019).

El presidente electo de la República Argentina resultó ser, finalmente, el candidato del Frente de Todos, Alberto Fernández. Fue la fuerza política más votada en la provincia, obteniendo un apoyo del $53 \%$ e imponiéndose en 18 de los 19 departamentos. La coalición Juntos por el Cambio alcanzó el 35\% de los votos totales y salió victoriosa únicamente en el distrito Capital. Al igual que en las PASO, la tercera fuerza política más votada, aunque muy lejos de las dos primeras, fue Consenso Federal con el 7,21\% de los sufragios totales. En cuanto al resto 
de las coaliciones/partidos políticos no lograron superar el restringido umbral del $2 \%$ de los votos.

Ahora bien, la Figura 3 evidenció una interesante tendencia producida en el transcurso de las PASO a las Generales en la provincia: el Frente de Todos logró incorporar solo 4.733 votos adicionales, pasando de un total de 237.327 a 242.060 sufragios finales. En contraste, Juntos por el Cambio aumentó sustancialmente su caudal electoral: pasando de 116.745 sufragios a 160.449 , incorporando un total de 43.704 nuevos votos. Ello se explica no solo a condición del cambio de estrategias del macrismo a nivel nacional, destacándose marchas multitudinarias en diferentes regiones del país y un gran acto masivo en la Ciudad de Buenos Aires, sino fundamentalmente porque la coalición Juntos por el Cambio logró capitalizar votos que en ocasión de las PASO fueron asumidos por otros frentes electorales. En San Juan, por ejemplo, el frente Consenso Federal disminuyó su apoyo electoral, pasando de 43.716 sufragios en las PASO a 33.004 en las Generales.

Figura 4.

Resultados Elecciones Generales, categoría Diputados Nacionales, por San Juan. Año 2019

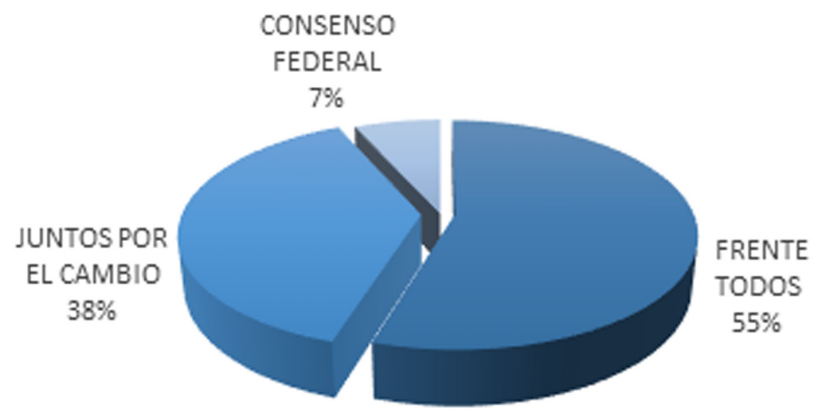

Fuente: Elaboración propia sobre la base de datos del Observatorio Político Electoral (2019).

En el plano legislativo, el Frente de Todos también resultó victorioso, logrando ubicar a sus dos principales candidatos en la Cámara Baja: Gioja y Caselles renovaron sus respectivos mandatos con casi un $55 \%$ de votos favorables. El respaldo electoral obtenido provino, fundamentalmente, de los departamentos Chimbas, Pocito y Rawson, donde superaron el $60 \%$. El tercer puesto en el Parlamento Nacional fue obte- 
nido por Marcelo Orrego, de Juntos por el Cambio, que se quedó con el $38 \%$ del electorado y sus principales apoyos vinieron de los departamentos Rivadavia y Santa Lucía. En tercer lugar, quedó Nancy Avelín de Consenso Federal, que no pudo obtener un lugar en la Cámara de Diputados.

\section{Discusión y conclusiones}

Enmarcado dentro del giro subnacional de los estudios de la sociología política, y a partir de la instrumentación articulada de fuentes documentales, estadísticas públicas y testimonios orales, este artículo procuró contribuir a la comprensión e indagaciones referentes a la dinámica electoral de San Juan durante 2019 y su intersección con el entramado nacional. Pero lejos de una interpretación del proceso político desde un enfoque meramente cuantitativo, centrado habitualmente en el peso provincial sobre el padrón electoral nacional, que difuminaría la importancia del caso sanjuanino, el trabajo fue abordado desde una perspectiva sociológica cualitativa y bajo la modalidad de un estudio de caso que procurara examinar las convergencias y concurrencias políticas devenidas en el territorio provincial y su relativa incidencia en la institucionalización de la contienda nacional. El principal argumento trabajado fue que la política provincial no constituyó un epifenómeno de lo nacional, adquiriendo más bien una propia singularidad y manteniendo una relevante interacción con los niveles de gobierno subprovincial y, especialmente, con el nacional.

El trabajo resulta relevante ante un concierto diverso de situaciones partidarias provinciales en un contexto federal como el argentino, aportando a identificar los partidos y actores que participaron del escenario político, sus rasgos distintivos e intereses, así como las estrategias por ellos desplegadas y sus puntos de interacción con los poderes estatales involucrados. Ahora bien, aunque el interés principal de este estudio de caso es habilitar la reflexión y el análisis sobre la configuración del espacio subnacional sanjuanino frente a la reciente contienda electoral, en términos relacionales consideramos que el caso presenta también un interés secundario frente a la posibilidad de teorizar en estudios posteriores referidos a situaciones más generales, que coadyuven a comprender la complejidad y la singularidad de otros espacios políticos provinciales que atraen también diversos 
actores que configuran la escena territorial en la que interactúan (sea nacional y/o subnacional). Particularmente, puede contribuir a ahondar/contrastar con casos similares (provincias de poco peso electoral cuantitativo como Santa Cruz, Formosa, San Luis, etc.) y también con casos diferentes (como Buenos Aires, Santa Fe o Córdoba) que podrían ser pensadas en la misma lógica epistemológica.

En cuanto a los hallazgos específicos del caso en estudio, cabe destacar que tradicionalmente las contiendas electorales en San Juan se han desplegado en el marco de una intensa relación-tensión respecto de la política nacional y la reciente competencia electoral no fue una excepción. A nivel provincial se disputaron importantes cargos ejecutivos y legislativos, pero en el marco de un escenario político complejo: el PJ Provincial (que atravesaba por un recambio importante de actores) procuraba reafirmar su posicionamiento dominante frente a un gobierno nacional de diferente signo político que disponía aquí de actores propios, quienes oficiando de oposición habían adquirido una competitividad creciente. En este sentido, cabe pensar que la relevancia del caso sanjuanino radica en que la conformación de las coaliciones políticas, especialmente del Frente Todos, el rol de doble-agentes de ciertos líderes provinciales y el mismo comportamiento electoral de la ciudadanía, oficiaron como una suerte de antesala de lo ocurrido meses después en la contienda nacional.

En el plano subnacional cabe destacar que la alianza electoral que encaró el PJ y sobre la que articuló la unidad de diversos actores y sectores intra y extrapartidarios fue la fórmula política que, erigida sobre las bases del anterior FPV, condujo al oficialismo provincial hacia un nuevo éxito electoral. En efecto, Uñac se consagró nuevamente como gobernador de San Juan con un 56\% del electorado a su favor, posicionándose en 13 de los 19 distritos departamentales. En ciertos tramos de este trabajo, hemos ilustrado algunas de estas disputas políticas del oficialismo provincial en espacios departamentales, mostrando la complejidad de lo político también a nivel local. De hecho, uno de los principales corolarios de la coyuntura electoral del 2019 ha sido la evolución de la morfología de las redes político-partidarias de San Juan, emergiendo una bisagra política en la trayectoria misma de sus actores. Si bien los resultados electorales reafirmaron el posicionamiento dominante del PJ en el escenario provincial, evidenciamos un fortale- 
cimiento de los sectores de la oposición y, en ambos casos, un reacomodamiento de sus estructuras partidarias a partir de un importante recambio de actores en un marco de mayor competitividad. De allí que el capital político en disputa no debe ser entendido solamente en términos del color partidario que se impuso o la lealtad del electorado hacia cierta coalición política, sino también en términos del perfil y peso adquiridos por los actores en la competencia.

Respecto de ello, vale destacar que José Luis Gioja, histórico líder del PJ y hasta entonces la figura política más influyente en el territorio provincial, fue dando paso (no sin roces) a la consolidación política de Sergio Uñac. Si bien Gioja mantiene vigencia política en su rol como diputado provincial y es reconocido y respetado por un importante sector del peronismo, Uñac ha sabido posicionarse en un lugar de privilegio dentro del armado provincial y nacional del peronismo. Por el lado de la oposición, el histórico referente ha sido Roberto Basualdo, pero desde que se asoció a Cambiemos durante las elecciones del 2015 y ocupa un lugar en el Senado, fue cediendo su lugar a un joven formado en las filas de su propio partido: Marcelo Orrego. Del análisis efectuado, se desprende que tanto Uñac como Orrego, el Frente Todos y el Frente Con Vos, el PJ y el nido de Cambiemos a nivel provincial, constituyen las dos fuerzas políticas que a la fecha cuentan con estructura partidaria en los 19 departamentos de San Juan, poseen clivajes importantes que los vinculan nacionalmente y, como quedó demostrado tras el análisis de los escrutinios finales, cuentan con competitividad electoral propia.

En cuanto a la intersección de la política provincial con la arena nacional, cabe destacar que desde el oficialismo de San Juan y desde el peronismo/kirchnerismo nacional contribuyeron a trasladar el modelo de armado político sanjuanino, considerado una buena estrategia electoral, hacia otras provincias y, por supuesto, también al escenario nacional. En este trabajo, hemos visto que San Juan fue una de las primeras provincias en promover acuerdos entre peronistas y kirchneristas y, de hecho, dos de sus principales referentes (Uñac y el exgobernador Gioja) se destacan entre los actores políticos que coadyuvaron a la reconstrucción de las redes de relaciones necesarias para la emergencia del también llamado Frente de Todos en la escala nacional, base sobre la cual la fórmula Fernández-Fernández labró la unidad de di- 
ferentes sectores y pudo recuperar finalmente la hegemonía del PJ a nivel del Estado nacional. En este sentido, uno de los principales aportes del trabajo ha sido mostrar cómo ciertos actores políticos, partidos y/o frentes situados a nivel subnacional desplegaron roles multinivel durante el contexto electoral, construyendo sus propias plataformas de poder, pero de forma relacional con la esfera nacional a la que contribuyeron a configurar. El análisis del caso sanjuanino ha resultado de gran interés porque, entre otras cosas, ha permitido precisamente identificar la conformación en espejo de coaliciones políticas triunfantes en la arena subnacional y nacional.

En suma, con este trabajo hemos procurado aportar conocimiento empírico sobre la reciente dinámica electoral argentina, operando un cambio en la habitual escala de análisis, centrándonos en una provincia no metropolitana del país (San Juan) y abordando un juego político complejo que ha implicado la activa participación de actores que "habitan" en distintos niveles de gobierno.

\section{Referencias}

Aelo, O. (2010). Las configuraciones provinciales del peronismo. Actores y prácticas políticas, 1946-1955. Instituto Cultural Archivo Histórico.

Albright, J. (2010). The multidimensional nature of party competition. Party Politics, 16(6), 699-719. https://doi. org/10.1177/1354068809345856

Algañaraz, V. y González, M. (2016). Cuarenta años. Voces del último golpe de Estado. Fondo Editorial de la Cámara de Diputados.

Alonso, L. (1999). La mirada cualitativa en sociología. Fundamentos.

Battle, M. (2009). Distribución territorial de los apoyos territoriales en América Latina: los casos de Ecuador, Perú y Honduras (1979-2006). Análisis Político, (67), 3-20. https://revistas. unal.edu.co/index.php/anpol/article/view/45809/47332

Bechtel, M. (2012). Not always second order: Subnational elections, national-level vote intentions, and volatility spillovers in a multi-level electoral system. Electoral Studies, 31(1), 170183. https://doi.org/10.1016/j.electstud.2011.10.005

Behrend, J. (2011). The unevenness of democracy at the subnational level. Latin American Studies Association, 46(1) 170-183. 
https://www.jstor.org/stable/41261374?seq=1\#metadata_ info_tab_contents

Benton, A. (2009). What makes strong federalism seem weak? Fiscal Resources and Presidential-Provincial Relations in Argentina. Publius: The Journal of Federalism, 39(4), 651-676. https://doi.org/10.1093/publius/pjn032

Bonvecchi, A. y Lodola, G. (2011). The dual logic of intergovernmental transfers: Presidents, governors, and the politics of coalitionbuilding in Argentina. Publius: The Journal of Federalism, 41(2), 179-206. https://doi.org/10.1093/publius/pjq024

Calvo, E. y Abal Medina, J. (Comps.) (2001). El federalismo electoral argentino: sobrerrepresentación, reforma politica y gobierno dividido en la Argentina. EUDEBA.

Calvo, E. y Escolar, M. (2005). La nueva política de partidos en Argentina: crisis politica, realineamientos partidarios y reforma electoral. PENT/Prometeo.

Cámara de Diputados de San Juan (03 de marzo de 2014a). Constitución de la Provincia de San Juan. https://diputadossanjuan. gob.ar/archivos/Constitucion_Provincial.pdf

Cámara de Diputados de San Juan (03 de marzo de 2014b). Nuevo Código Electoral de la Provincia de San Juan. Última actualización. https://diputadossanjuan.gob.ar/leyes-sancionadas/ item/5024-ley-n-8520

Cámara Nacional Electoral (03 de marzo de 2019). Electores habilitados para votar en las Elecciones Generales del 2019. https://www. electoral.gob.ar/nuevo/paginas/datos/padrondatos2019. php

Cao, H. (2013). Ajuste estructural y política en la Provincia de San Juan. El primer sanjuaninazo. Revista Perspectivas de Políticas Públicas, 2(4), 189-219. https://doi.org/10.18294/ rppp.2013.627

Ceretti, G., Navarro, M., Bocelli, N., y Veramendi, M. (2015). El voto Sanjuanino. Del pluralismo al predominio partidario. Comportamientos ciudadanos y sistemas de partidos en la Provincia de San Juan, 1983-2011. Editorial Fundación de la Universidad Nacional de San Juan.

Cherny, N. y Vommaro, G. (2004). Territorios, liderazgos, partidos: la política argentina a nivel subnacional. En I. Cheresky y J. M. 
Blanquer (Eds.), ¿Qué cambió en la política argentina? (pp. 147-178). Ediciones Homo Sapiens.

Clarín (8 de noviembre de 2018). Otra provincia peronista desdobla su elección: el 2 de junio se votará en San Juan. Clarín. https:// www.clarin.com/politica/provincia-peronista-desdoblaeleccion-junio-votara-san-juan_0_OTbVlD4hu.html

Clarín (11 de junio de 2019). A un día del cierre de alianzas, Sergio Massa y José Luis Gioja juntos para la foto del acuerdo con el kirchnerismo. Clarín. https://www.clarin.com/politica/ sergio-massa-jose-luis-gioja-juntos-foto-acuerdo-kirchnerismo_0_XSK3ziKBw.html

Congreso de la Nación Argentina (2020). Constitución Nacional. https://www.congreso.gob.ar/constitucionNacional.php

Cruz, F. (2014). ¿Socios de menor nivel? Aportes para el estudio de las coaliciones subnacionales en sistemas políticos multinivel. Revista Uruguaya de Ciencia Política, 23(1), 11-39. http://www.scielo.edu.uy/scielo.php?script=sci_ arttext\&pid=S1688-499X2014000100001

Diario de Cuyo (28 de septiembre de 2018). Aranda y el freno judicial: a la oposición no le importan los árboles, solo hacer política. Diario de Cuyo. https://www.diariodecuyo.com.ar/sanjuan/ Aranda-y-el-freno-judicial-A-la-oposicion-no-le-importanlos-arboles-solo-hacer-politica-20180928-0028.html

Diario de Cuyo (10 de enero de 2019a). La palabra de Sergio Uñac tras presentar el "Frente Todos". "Queremos diferenciarnos de una política nacional que oprime las esperanzas". Diario de Cuyo. https://www.diariodecuyo.com.ar/politica/Se-presenta-elFrente-Todos-en-un-hotel-centrico-20190110-0024.html

Diario de Cuyo (6 de junio de 2019b). Escrutinio definitivo: así fue el resultado de la elección de cada uno de los intendentes. Diario de Cuyo. https://www.diariodecuyo.com.ar/especiales/ elecciones-san-juan-2019/

Diario Perfil (3 de junio de 2019). ¿Quién es Sergio Uñac? La promesa peronista que ahora apoya a los Fernández. Diario Perfil. https:// www.perfil.com/noticias/politica/elecciones-2019-san-juanquien-es-sergio-unac-promesa-peronista-apoya-los-fernandez.phtml

Došek, T. y Freidenberg, F. (2013). La congruencia de los partidos y los sistemas de partidos multinivel en América Latina: concep- 
tualización y evaluación de algunas herramientas de medición. Politai: Revista de Ciencia Política, 4(7), 161-178. http:// revistas.pucp.edu.pe/index.php/politai/article/view/13903

Dulzaides, M. y Molina, A. (2004). Análisis documental y de información: dos componentes de un mismo proceso. ACIMED, 12(2), 1-5. http://scielo.sld.cu/pdf/aci/v12n2/aci11204.pdf

El Destape (29 de mayo de 2019). Elecciones 2019. El elogio de Sergio Uñac en apoyo a Cristina Kirchner. El Destape. https://www. eldestapeweb.com/c60625

Ferrari, M. (2017). Democracia Cristiana, Partido Justicialista y política de frentes. El FREJUDEPA en perspectiva histórica. Boletín del Instituto de Historia Argentina y Americana Dr. Emilio Ravignani, (48), 53-121. http://ppct.caicyt.gov.ar/index. $\mathrm{php} /$ ravignani/article/view/12074/10724

Ferrari, M. y Mellado, V. (2015). La renovación peronista en clave subnacional. Organización partidaria, liderazgos y dirigentes en democracia. Editorial de la Universidad Nacional de Tres de Febrero, EDUNTREF.

Field, B. y Siavelis, P. (2009). Procedimientos de selección de candidatos en las democracias nacientes. En F. Freidenberg y M. Alcántara Sáez (Comps.), Selección de candidatos, politica partidista y rendimiento democrático (pp. 61-84). Tribunal Electoral del Distrito Federal.

Frederic, S. y Soprano, G. (Comps.) (2009). Política y variaciones de escalas en el análisis de la Argentina. Prometeo.

Freidenberg, F. y Suárez-Cao, J. (Comps.) (2014). Territorio poder: nuevos actores y competencia política en los partidos multinivel en América Latina. Ediciones Universidad de Salamanca.

Gervasoni, C. (2011). Democracia, autoritarismo e hibridez en las provincias argentinas: la medición y causas de los regímenes subnacionales. Journal of Democracy en Español, (3), 75-93. http://historiapolitica.com/datos/biblioteca/gervasoni.pdf

Gibson, E. y Suárez-Cao, J. (2010). Federalized party systems and subnational party competition: Theory and empirical application to Argentina. Comparative Politics, 1(43), 21-39. https:// doi.org/10.5129/001041510x12911363510312

Gibson, E. (2012). Boundary control: Subnational authoritarianism in federal democracies. Cambridge University Press. 
Goldberg, M., Castilla, M., Gómez, N. y Henríquez, M. G. (2007). Del cantonismo al bloquismo (Informe Final de Proyecto de Investigación). Universidad Nacional de San Juan.

Goldberg, M., Castilla, M., Gómez, N. y Henríquez, M. G. (2009). El juego de las sillas. Estrategias de reproducción en el campo político sanjuanino. Fundación Universidad Nacional de San Juan.

Gómez, N. y Goldberg, M. (2013). La reconfiguración del campo político en San Juan. Una aproximación a los gobiernos de Cantoni y Bravo. RevIISE - Revista de Ciencias Sociales y Humanas, (4), 57-66. http://www.ojs.unsj.edu.ar/index.php/reviise/ article/view/41

Jeffery, C. y Schakel, A. (2012). Insights: Methods and data beyond methodological nationalism. Regional Studies, 47(3), 1-3. https://doi.org/10.1080/00343404.2013.746444

La Nación (9 de mayo de 2011). San Juan habilitó la reelección de Gioja. La Nación. https://www.lanacion.com.ar/politica/sanjuan-habilito-la-reeleccion-de-gioja-nid1371797

La Nación (3 de junio de 2019). Orrego tomó distancia de Cambiemos y está en duda su candidatura en octubre. La Nación. https:// www.lanacion.com.ar/politica/orrego-tomo-distancia-decambiemos-y-esta-en-duda-su-candidatura-en-octubrenid2254037

La Política on line (23 de junio de 2017). Gioja bajó la candidatura a Senador y destrabó el acuerdo con Uñac. La Política on line. https://www.lapoliticaonline.com/nota/106353-gioja-sebajo-de-la-candidatura-a-senador-y-destrabo-el-acuerdocon-unac/

Leiras, M. (2006). Parties, provinces and electoral coordination: A study on the determinants of party and party system aggregation in Argentina, 1983-2005 [Tesis de doctorado]. https://curate. nd.edu/downloads/und:cv43nv9589h

Lodola, G. (2010). The politics of subnational coalition building. Gubernatorial redistributive strategies in Argentina and Brazil [Tesis de doctorado]. http://d-scholarship.pitt.edu/10257/1/ lodolagj_etd2010.pdf

Marradi, A., Archenti, N., y Piovani, J. (2007). Metodología de las ciencias sociales. Emecé.

Mauro, S. (2020). Coaliciones electorales y nuevos partidos políticos en Argentina. El caso de Propuesta Republicana. Convergencia 
Revista de Ciencias Sociales, (27), 1-24. https://www.redalyc. org/jatsRepo/105/10562755016/index.html

Mauro, S., Ortiz de Rozas, V., y Paratz Vaca Narvaja, M. (2016). Política subnacional en Argentina: enfoques y problemas. Centro de Estudios en Ciudadanía, Estado y Asuntos Públicos, CEAPUniversidad de Buenos Aires, UBA.

Micozzi, J. P. (2009). The electoral connection in multi-level systems with non-static ambition [Tesis de doctorado). https://scholarship.rice.edu/handle/1911/61922

Observatorio Político Electoral (2019). Resultados electorales 2019 San Juan. Ministerio del Interior. Presidencia de la Nación. https://www.argentina.gob.ar/analisis-politico-electoral/ san-juan

Oliveros, V. y Scherlis, G. (2004). ¿Elecciones concurrentes o selecciones desdobladas? La manipulación de los calendarios electorales en la Argentina, 1983-2003. En I. Cheresky y J. M. Blanquer (Comps.), ¿Qué cambió en la política argentina? (pp. 179-210). Homo Sapiens.

Ortiz de Rozas, V. (2016). La democracia argentina en clave subnacional: nuevos objetos de estudio e interpretaciones sobre el Estado, los partidos políticos y las elites políticas. En S. Mauro, V. Ortiz de Rozas, y M. Paratz Vaca Narvaja (Comps.), Política subnacional en Argentina: enfoques y problemas (pp. 33-54). Centro de Estudios en Ciudadanía, CEAP-Universidad de Buenos Aires, UBA. http://biblioteca.clacso.edu.ar/Argentina/ceap/20170405023837/PoliticaSubnacional.pdf

Ortiz de Rozas, V. y Rodrigo, C. (2017). Presentación: política subnacional, perspectivas teóricas y desafíos empíricos. Revista Sudamérica, (6), 9-13. https://fh.mdp.edu.ar/revistas/index.php/ sudamerica/article/view/2272/2375

Poder Ejecutivo de San Juan (2018). Decreto No 1979/18. Convocatoria a elecciones provinciales. Publicado en el Boletín Oficial del Gobierno de San Juan el 08/11/2018. https:// contenido.sanjuan.gob.ar/index.php?option $=\mathrm{com}_{-}$ k2\&view=item \&id=6487:boletin-oficial-de-08-112018\&Itemid $=148$

Pereyra, D. y Vasini, S. (1994). El bloquismo sanjuanino. En P. Lacoste (Comp.), Populismo en San Juan y Mendoza (pp. 41-109). Centro Editor de América Latina. 
Piovani, J. y Muñiz Terra, L. (2018). ¿Condenados a la reflexividad? Apuntes para repensar el proceso de investigación social. Consejo Latinoamericano de Ciencias Sociales, CLACSO.

Puente, M. (2017). Continuidad y disputas internas en el peronismo de San Juan. En S. Mauro y J. Lenarduzzi (Comps.), La venganza de los huérfanos: las elecciones nacionales y subnacionales de 2015 en Argentina (pp. 451-460). Universidad de Buenos Aires. http://ceap.sociales.uba.ar/2017/06/08/la-venganzade-los-huerfanos-las-elecciones-nacionales-y-subnacionales-de-2015-en-argentina/

Rodrigo, C. (2014). Relaciones de gobierno e inestabilidad. El juicio político en la escala subnacional. Revista Mexicana de Análisis Político y Administración Pública, 3(2), 125-154. https:// biblat.unam.mx/hevila/Revistamexicanadeanalisispoliticoyadministracionpublica/2014/vol3/no2/6.pdf

Rodrigo, C. (2018). Gobernadores sin gobierno. Destituciones mediante juicio político en San Juan. Editorial Teseo-Universidad. https://www.teseopress.com/Gobernadores/back-matter/ bibliografia/

Rodrigo, C. (2019). Actores y escalas en la construcción del Frente Para la Victoria San Juan. Revista Pilquen, 22(3), 13-26. https:// dialnet.unirioja.es/servlet/articulo? codigo $=5083763$

Ruffa, M. y López, C. (2005). El sanjuaninazo. Autor.

Santander, P. (2011). Por qué y cómo hacer análisis de discurso. Cinta de moebio, (41), 207-224. https://dx.doi.org/10.4067/S0717$554 \mathrm{X} 2011000200006$

Sautu, R. (2003). Todo es teoría. Lumiere.

Snyder, R. (2001). Scaling down: The subnational comparative method. Studies in Comparative International Development, 36(1), 93-110. https://doi.org/10.1007/BF02687586

Stefuriuc, I. (2009). Government formation in multi-level settings: Spanish regional coalitions and the quest for vertical congruence. Party Politics, 15(1), 93-115. https://doi. org/10.1177/1354068808097895

Tiempo de San Juan (19 de mayo de 2019). Alberto Fernández: "San Juan ha sido el modelo a seguir". Tiempo de San Juan. https:// www.tiempodesanjuan.com/politica/2019/5/19/albertofernandez-san-juan-ha-sido-el-modelo-seguir-255228.html 
Tribunal Electoral de San Juan (2019). Cronograma electoral y resultados de escrutinios 2019. Poder Judicial de la Provincia de San Juan.

Veramendi, M. (2009). Auge y declinación: trayectoria electoral del bloquismo y Cruzada Renovadora en veinte años de democracia. Revista Estudios, (22), 209-230. https://dialnet.unirioja.es/descarga/articulo/5209667.pdf

Yin, R. (1994). Case study research: Design and methods. Sage Publications. 